\title{
Electrochemical Deposition of Ni, NiCo Alloy and NiCo-Ceramic Composite Coatings-A Critical Review
}

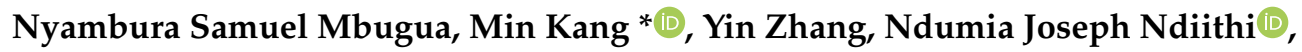 \\ Gbenontin V. Bertrand and Liang Yao \\ College of Engineering, Nanjing Agricultural University, Nanjing 210031, China; \\ 2017112123@njau.edu.cn (N.S.M.); 2018212003@njau.edu.cn (Y.Z.); 2017112122@njau.edu.cn (N.J.N.); \\ 2019212016@njau.edu.cn (G.V.B.); 2018112003@njau.edu.cn (L.Y.) \\ * Correspondence: kangmin@njau.edu.cn; Tel.: +86-25-5860-6578
}

Received: 1 July 2020; Accepted: 3 August 2020; Published: 6 August 2020

\begin{abstract}
In recent years, alloy and alloy-ceramic coatings have gained a considerable attention owing to their favorable physicochemical and technological properties. In this review, we investigate $\mathrm{Ni}$, $\mathrm{NiCo}$ alloy and $\mathrm{NiCo}-$ ceramic composite coatings prepared by electrodeposition. Electrodeposition is a versatile tool and cost-effective electrochemical method used to produce high quality metal coatings. Surface finish and tribological properties of the coatings can be further improved by the addition of suitable agents and control of deposition operating conditions. In this review, $\mathrm{Ni}, \mathrm{NiCo}$ alloy and $\mathrm{NiCo}-$ ceramic composite coatings prepared by electrodeposition are reviewed by critically evaluating previous researches. The use of the coatings and their potential for future research and development are discussed.
\end{abstract}

Keywords: nanostructured coatings; microhardness; corrosion resistance; electrochemical deposition

\section{Introduction}

Materials are a fundamental pillar in engineering technology. The materials' electrochemical, thermal and mechanical interaction begins on the surface. However, material surfaces face the constant threat of wear and corrosion resulting in massive losses in industry. The use of surface enhancement technology to prevent or mitigate the loss has therefore become inevitable. Over the last few decades, major scientific development in the fields of metallurgy and materials has occurred, giving rise to new engineering materials with superior properties. Developing suitable processing to produce desired materials is complex and requires altering the inherent properties of the materials. Consideration is made of the overall economic perspective and its environmental impact.

Electrodeposition is an electrochemical process that is used to modify the surface structure. Use of electrodeposition in surface engineering can be traced to nearly 200 years ago based on some hypotheses [1]. The galvanic cell, invented in early 1800's, paved way for use of electric current to produce coatings as a more cost-effective technique. The electrodeposition technique possesses an edge over other coating techniques due to several reasons [2]:

(i) Low initial investment coupled with high rate of production.

(ii) It can be used with a wide variety of shapes and sizes of substrates

(iii) Ease of producing economically viable quantities of nanocomposite materials, with grain sizes as small as $10 \mathrm{~nm}$.

(iv) Products of electrodeposition require no further processing and can be used immediately after the process. 
(v) It is an easy concept that can be replicated in industry and laboratories with minimal technological barriers.

(vi) Electrodeposited $\mathrm{Ni}$ coatings have exhibited superior density and lower porosity.

Electrodeposition is based on the principle that a layer of coating, either single or multilayer, forms as a result of the electrode-electrolyte electrochemical reactions occurring leading to electrodeposition of ions contained in electrolyte. It utilizes the properties of materials in their metastable state as a result of reduction of the grain size on the nano scale. In such a state, the grain boundaries contain a proportion of atoms that is higher or equivalent to those inside the grains [3]. These new types of materials consisting of nanoparticles are referred to as nanocomposite materials and they exhibit superior properties compared to traditional grain sized materials and sometimes offer completely new properties altogether. As a result, nanocomposite materials with grain sizes below $100 \mathrm{~nm}$ have received considerable attention from scientists and researchers all over the world. Several new electrodeposition synthesis methods have been devised over the years to increase production efficiency of new materials and minimize cost. This has ranged from using the basic direct current set ups to more ambitious procedures such as: pulse plating, jet electrodeposition, and the pulse reversal current technique [4-6].

Pure Ni is one of the most widely used alloying metals in the world owing to its superior corrosion and wear resistance [7]. Electrodeposited Ni coatings have uses in decoration, functional uses, as well as in engineering for surface protection [8]. Superplasticity in metals (materials exhibiting increased elongations to failure of $>500 \%$ ) is dependent on elevated testing temperatures and fine grain sizes of $<10 \mu \mathrm{m}$ [9]. Prasad and Chokshi [9] reported that electrodeposited nanocrystalline $\mathrm{Ni}$ is characterized by good superplasticity properties and is used in studying the phenomenon in electrodeposited metals owing to the ease of synthesizing coatings with small grain sizes. Ni coatings exhibit improved resistance to localized corrosion and this makes them perfect for use as anti-corrosive coatings [2]. Furthermore, research shows that thin films of different materials coated with epitaxial thin Ni coatings of a few nanometers have similar hardness to bulk nickel, such that the wear resistance of micro/nano electro mechanical system devices can be greatly improved if coated with a thin Ni coating [10]. Studies have shown that nano-sized nickel can aid the diamond yielding process. $\mathrm{Ni}$ atoms have a three dimension absent state which serves to attract electrons in the carbon fullerenes. This in turn causes the sp2 fullerene to be transformed into a diamondlike sp3 structure. This transformation can also be attributed to high reactivity which effectively aids the change at an impulse during shock wave loading [2].

$\mathrm{Ni}$ based alloy coatings can also be produced using electrodeposition. Choice of the alloying metal depends on the properties desired, which can range from good electrical conductivity, good wear and corrosion resistance, soft magnetic properties to special optical properties. Over the years, many different types of metals have been electrodeposited with $\mathrm{Ni}$ to form alloys: $\mathrm{Co}, \mathrm{Fe}, \mathrm{Cu}$ and $\mathrm{W}$.

$\mathrm{Ni}-\mathrm{Co}$ is one such alloy. There exist several different synthesis techniques for $\mathrm{Ni}-\mathrm{Co}$ alloy coatings and they include: radio frequency magnetron sputtering [11], electrodeposition [12] and vacuum evaporation $[13,14]$. The electrodeposition technique has several advantages over the other two methods and they include: low cost, simplicity, scalability and manufacturability [15]. Furthermore, electrodeposition can be used to grow a wider range of materials.

Research shows that electrodeposited Ni-Co alloy coatings exhibit better properties compared to pure Ni coatings [12]. Ni-Co alloy exhibits higher hardness, better adhesion, excellent magnetic properties, high wear and corrosion resistance as well as good stability at high temperature [16-19]. Wang et al. [20] researched the effect of cobalt content on mechanical and microstructural properties on $\mathrm{Ni}-\mathrm{Co}$ alloy coatings. It was reported that $\mathrm{Ni}-\mathrm{Co}$ alloy coatings exhibited approximately double the microhardness when compared to pure $\mathrm{Ni}$ coatings. It was also reported that the $\mathrm{Ni}-49 \mathrm{Co}$ coatings exhibited a decreased rate of wear in comparison to pure Ni coatings. Hassani et al. [21] researched on low temperature superplasticity of nanocrystalline electrodeposited Ni-Co alloy with an average grain size of $20 \mathrm{~nm}$. It was reported that a maximum elongation of $279 \%$ at a temperature of $773 \mathrm{~K}$ was 
obtained. Ni-Co alloys are considered to be the best suited materials for replacing hard chromium [22]. Research shows that microhardness in Ni-Co alloys increases gradually with increase in Co content up to an optimum level, after which the microhardness decreases with further increase in Co content [16].

To further improve the properties of $\mathrm{Ni}-\mathrm{Co}$ alloy coatings, nanoparticles have been suspended in electrolyte and they become embedded into the electro-formed solid phase layer during electrodeposition [23]. In such materials, the inherent properties of the nanoparticles have been found to significantly influence the overall properties of the nanocomposite coatings. Many different types of nanoparticles have been electrodeposited with $\mathrm{Ni}-\mathrm{Co}$ alloy including $\mathrm{SiC}, \mathrm{Al}_{2} \mathrm{O}_{3}, \mathrm{SiO}_{4}, \mathrm{ZrO}_{2}$, $\mathrm{Cr}_{2} \mathrm{O}_{3}, \mathrm{Si}_{3} \mathrm{~N}_{4}$ and $\mathrm{TiO}_{2}$ [24]. These nano particles used in electrodeposition can be classified as either hard materials or soft materials depending on the desired properties. Soft materials such as graphite offer properties which include lower the friction coefficient to reduce wear and the coefficient of friction between shearing surfaces [25]. Hard materials such as $\mathrm{Al}_{2} \mathrm{O}_{3}$ improve the microhardness and wear resistance of surfaces [26]. The matrix phase microstructure coupled with nanoparticle content and distribution in the metallic matrix phase significantly influences the properties of nanoparticle reinforced Ni-Co matrix nanocomposite coatings. From past research, it is clear that addition of nanoparticles has served to improve the properties of Ni-Co coatings. In some instances, however, addition of $\mathrm{Co}$ has been observed to improve the overall properties of Ni-nanocomposite coatings such as hardness and residual stress [27]. Addition of $\mathrm{Co}^{2+}$ in Ni/diamond plating baths has been seen to greatly improve the deposition of diamond in the coatings resulting in higher diamond content, enhance bonding between matrix and particles, as well as more uniformly dispersed particles in the metal matrix, resulting in improved wear resistance and hardness properties [28]. The properties of $\mathrm{Ni}-\mathrm{Co}$ alloys and their composite coatings have also been previously reported on by Karimzadeh A et al. [29]. This review aims takes a different approach to the wide research field of Ni-Co and $\mathrm{Ni}-\mathrm{Co}$-based composite coatings. Factors such as the effect of electrode orientation and forces existing in the electrolyte bath on the deposition process have been considered. Moreover, additives such as boric acid have been extensively explored, and the intricate working of the Watts solution has been more deeply discussed for easier understanding. Properties such as adhesion between substrate and coating have been extensively discussed, comparisons between techniques drawn, and recommendations for further adhesion improvement have been presented.

\section{Electrodeposition Methods}

\subsection{Direct Current Electrodeposition}

In Direct current (DC) electrodeposition, an electric current is continuously transferred through the system without any interruptions. DC electrodeposition is divided into two types depending on the orientation of the electrodes in electrolyte during the electrodeposition process. These are the conventional electrodeposition, and sediment codeposition (SCD) techniques. For conventional electrodeposition, the electrodes are placed vertically in the electrolyte, but for SCD they are placed horizontally. Adsorption of nanoparticles into the alloy matrix during electrodeposition is greatly influenced by forces acting on the suspended nanoparticles. The kinetics involved can be used to explain this difference. The two main forces at work during SCD electrodeposition are gravitational pull and the electrophoresis force, thereby giving more desirable properties compared to conventional deposition which solely relies on gravitational pull [30]. DC has several advantages over pulse electrodeposition and pulse reversal current (PRC) electrodeposition. These include simplicity, the availability of vast technical knowledge and affordability. Borkar T [31] reported that for all Ni and Ni nanocomposite coatings deposited, DC deposited coatings exhibited much stronger (less random) crystallographic textures compared to coatings deposited using PC and PRC deposition techniques. Furthermore, in DC electrodeposition, the Co content in the deposited Ni-Co coatings is dependent on the composition of the electrolyte, unlike in jet electrodeposition where Co electrodeposition is controlled by diffusion [4]. 


\subsection{Pulse Current Electrodeposition}

Pulse current electrodeposition (PC) has been used extensively over the years in Ni-Co electrodeposition [32]. The three most fundamental parameters that affect the properties of the coatings include in pulse current electrodeposition include: peak current $\left(I_{\text {peak }}\right)$, pulse imposition time (ON-time, $T_{O N}$ ) and switch off time (OFF-time, $\left.T_{O F F}\right)$. These parameters relate mathematically to evaluate (1) pulse frequency, (2) duty cycle, and (3) average current density, as shown [32,33]:

$$
\begin{gathered}
f=\frac{1}{T_{\text {OFF }}+T_{O N}} \\
\gamma=\frac{T_{O N}}{T_{O F F}+T_{O N}} * 100 \\
I_{\text {avg }} \frac{T_{O N}}{T_{O F F}+T_{O N}} * I_{\text {peak }}=I_{\text {peak }}
\end{gathered}
$$

where $\gamma$ is the duty cycle, $f$ the frequency, $I_{\text {peak }}$ the peak current density, and $I_{\text {avg }}$ the average current density.

In pulse electrodeposition, peak current density has a significant effect on microhardness, crystallite size, surface morphology, microstructure, composition, and tensile strength of PC deposited Ni-Co alloys and their nanocomposites [34]. Crystallization and growth in turn determine the microstructure of the nanocomposite. The texture of the coatings is determined by both peak current density and organic surfactants [35]. The quantity of adatoms located at the surface is higher due to the applied higher current density as compared to DC electrodeposition. This results in smaller grain sizes [5]. Padmanabhan [36] reported that pulse electrodeposition is used as an effective method for the reduction of grain sizes to nanoscale [5].

Although it is a relatively low-cost synthesis technique with simple implementation, pulse electrodeposition is ideal for production of full density nanocrystalline materials [33]. Yang and Cheng [32] reported that the morphology of the deposited coatings changed from nodular to acicular, and a finer grain size was observed with increasing pulse frequency and decreasing duty cycle. It has also been reported that at low current densities, smoother surface morphologies are observed [37], but an increase in peak current density produces distinct colony-like morphologies characterized by clearer colony boundaries [34].

Pulse electrodeposition exhibits several advantages over DC electrodeposition, such as improved wear resistance and hardness, particle distribution, structure, morphological structure and the ability to control the grain sizes of the deposits [38]. PC electrodeposition has higher instantaneous current density compared to DC electrodeposition, thereby increasing its effectiveness in agitating the adsorption-desorption processes that occur at the Ni electrolyte interface. This makes it possible to control the electrodeposited Ni coating microstructure [39,40]. It has also been reported that PC deposits contain a higher nanoparticle content compared to coatings deposited by the DC deposition technique [31]. Yang and Cheng [32] concluded that the high microhardness of deposited Ni-Co-SiC coatings was primarily associated with increasing $\mathrm{SiC}$ content in the coatings with increasing pulse frequency and decreasing duty cycle. This significantly increased the microhardness as a function of the dispersion strengthening mechanism. Watts type baths used for pulse plating of Ni based coatings have been reported to produce the best coating results [2].

The PC deposition technique suffers from a drawback called the double layer capacitance effect. The double charging layer of the electrodes is subjected to charging and discharging occurrences. In a case where the ON- and OFF-times are much shorter than the charging and discharging times, the PC would revert to DC current. As such, care is taken to select a high frequency thus ensuring the effect of the double layer capacitance effect is negligible. 


\subsection{Jet Electrodeposition}

In this technique, a jet of plating solution is directed at the cathode surface directly. There exists an electrical field between the anode (located in the nozzle) and cathode (substrate). Figure 1 is a schematic representation of jet electrodeposition technique setup [4].

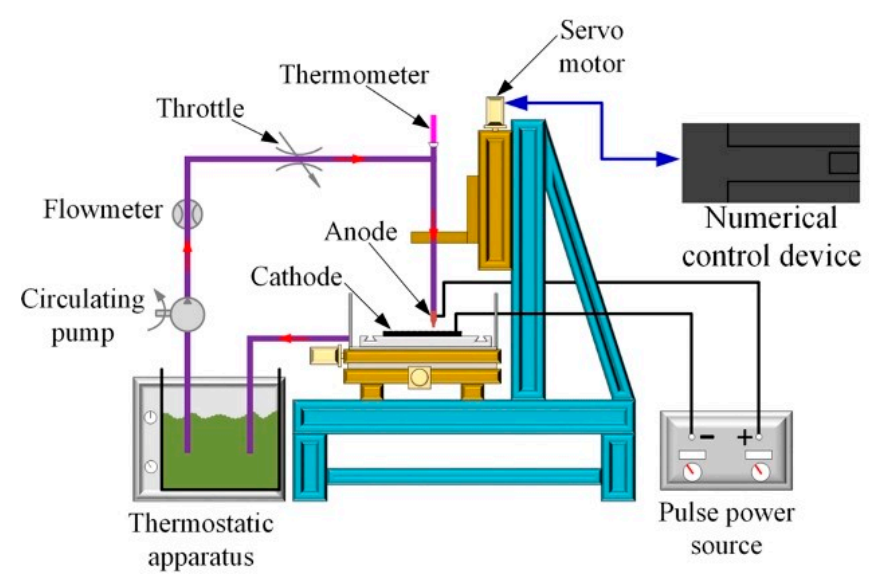

Figure 1. Schematic image of pulse jet electrodeposition.

As the plating solution flows, electric current is transferred along the stream of fluid to the substrate surface, thereby enabling deposition to occur on the cathode surface where the jet flows over [41]. Jet electrodeposition is a high-speed electroplating technique that offers a wide range of advantages [4]. These include: (i) a higher deposition rate compared to other conventional electrodeposition techniques, and (ii) a more efficient grain size refining effect. This is attributed to the cathode in the jet technique having a larger overpotential that can be used simultaneously with higher current densities. In this technique, Co content in the coatings increases with increases in electrolyte jet speed, $\mathrm{Co}^{2+}$ ion concentration in the electrolyte, and cathodic current density.

\subsection{Pulse Reversal Current Electrodeposition}

There are nine waveform parameters that can be used to represent the waveform characteristics according to the definition of bidirectional pulse parameters: (i) forward conduction time $t_{c}$, (ii) reverse conduction time $t_{d}$, (iii) forward peak current density $I_{p+}$, (iv) reverse peak current density $I_{p-},(\mathrm{v})$ average current density $I_{a v}$, (vi) pulse period $T$, (vii) reverse current coefficient $x$, (viii) duty cycle $\lambda$, and (ix) frequency $f$ [42]. The nine parameters are interrelated and they do not change independently. Where average current density $I_{a v}$, duty cycle $\lambda$, reverse pulse coefficient $x$, and frequency $f$ are considered as the independent variables, the parameters can be related mathematically, as shown in Equations (4)-(12) [43]:

$$
\begin{gathered}
I_{p+}=\frac{I_{a v}}{x \lambda+\lambda-x} \\
I_{p-}=x I_{p+} \\
t_{c}=\lambda T=\frac{\lambda}{f} \\
t_{d}=T-t_{c}=\frac{1-\lambda}{f} \\
T=t_{c}+t_{d} \\
I_{a v}=\frac{t_{c} I_{p+}-t_{c} I_{p-}}{T} \\
\lambda=\frac{t_{c}}{t_{d}}
\end{gathered}
$$




$$
\begin{gathered}
x=\frac{I_{p-}}{I_{p+}} \\
f=\frac{1}{T}
\end{gathered}
$$

Figure 2 shows the schematic diagram of a typical pulse-current wave form when $I_{a v}=15 \mathrm{~A} \cdot \mathrm{dm}^{2}$, $\lambda=0.5, x=0.5$, and $f=10 \mathrm{~Hz}$.

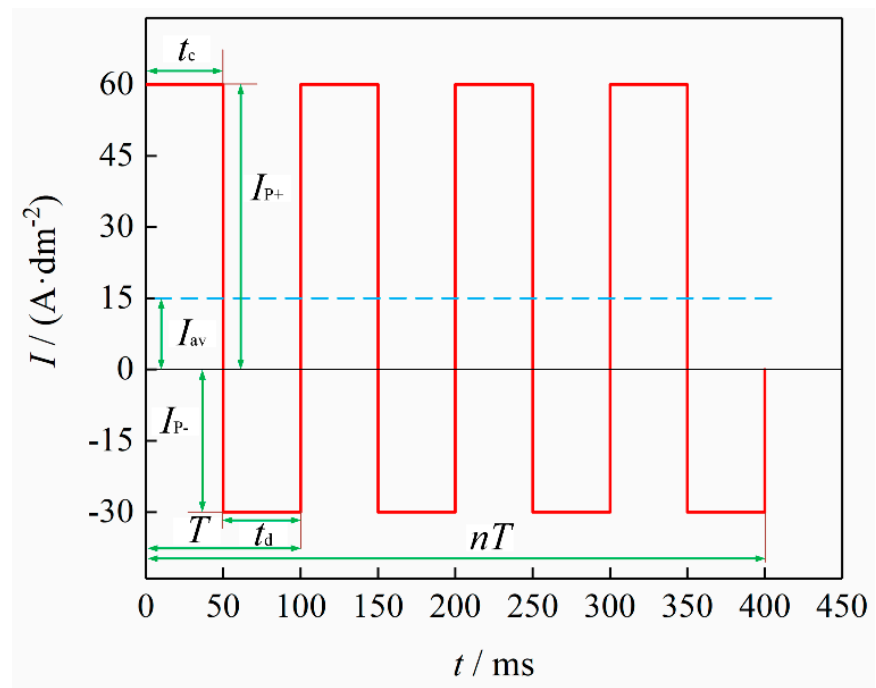

Figure 2. Schematic diagram of pulse waveform when $I_{a v}=15 \mathrm{~A} \cdot \mathrm{dm}^{2}, \lambda=0.5, x=0.5$, and $f=10 \mathrm{~Hz}$.

Pulse reversal current (PRC) electrodeposition has been used over the years owing to its unique ability to enhance nanoparticle incorporation in electrodeposited composite coatings, with the highest reported content being $23 \mathrm{wt} \%$ [44-46]. Ni-Co coatings produced using the PRC synthesis technique have been reported to exhibit higher hardness, better anti-wear properties, more compact surfaces, lower residual macro stress and better compact surfaces than those produced using DC and PC electrodeposition techniques $[6,40]$. In particular, the hardness improvement has been attributed to increased distribution of nanoparticles in the deposited Ni-Co matrix. As for lower residual macro stress, PRC deposits are characterized by uniform coatings since the technique hinders thickening of the corners and edges, as is common with DC electrodeposition. It can also be postulated that adsorption of $\mathrm{H}$ atoms by the deposited coatings is suppressed by pulse intervals and reversal current in PRC technique [40]. PRC deposited Ni-Co nanocomposite coatings possess smoother surfaces, finer Ni matrix crystals, and smaller grain sizes compared to DC technique deposited coatings [40].

The smooth surfaces coupled with high hardness increase the load-carrying capacity of $\mathrm{Ni}-\mathrm{Co}$ nanocomposite coatings and thereby improves their wear resistance properties. The lower macro-residual stress also plays a great part in wear resistance, where it causes lower brittleness and higher toughness in the coatings, and this decreases the rate of nanoparticle flaking and metal matrix peeling during wear testing [40]. PRC technique can be used in ultrasonic power conditions and this presents desirable effects on deposited Ni-Co coatings $[47,48]$. Overall, it presents several advantageous effects on the electrochemical process:

(i) Hindering sundries adsorption thereby altering the reaction mechanism,

(ii) An increase in exchange current density,

(iii) Lowering cathodic polarization,

(iv) Current efficiency and yield improvements, and

(v) (Strengthening conversion and diffusion.

It has been reported that $\mathrm{Ni}$-Co nanocomposite coatings electrodeposited using the PRC technique subject to ultrasonic conditions present finer grained, compact, and uniform coatings [6]. 


\section{Electrodeposition Parameters for Ni-Co Alloys}

\subsection{Effect of Co Concentration in Electrolyte}

Cobalt content has been reported to increase with increase in Co concentration in the electrolyte bath $[12,49]$. For Ni-Co deposition, $\mathrm{Ni}$ and Co combine to form a solid solution that engulfs the nanoparticles suspended in the electrolyte. As such, the higher the concentration of Co element in the electrolyte, the more formation of this solid solution matrix occurs on the cathode surface. Variation of $\mathrm{Co}^{2+}$ in the electrolyte has significant effects on grain sizes, and cobalt content of the electrodeposited $\mathrm{Ni}-\mathrm{Co}$ alloys and nanocomposites. Grain refinement can be explained using two approaches. Firstly, a lattice strain is produced as a result of the difference in atomic sizes of $\mathrm{Co}$ and $\mathrm{Ni}$. As the content of $\mathrm{Co}$ increases, the lattice distortion becomes aggravated causing vacancy and dislocation defects in the lattice. Grain size refinement is a direct consequence of these defects.

Secondly, as a result of anomalous deposition of $\mathrm{Co}$, the deposited Co content is higher than the corresponding concentration of $\mathrm{Co}$ in the electrolyte $[49,50]$. In this process, the less noble element (Co in this case) is reduced preferentially, resulting in a much higher content. This increase in content reaches a critical value, beyond which the microstructure of the electrodeposited coating changes from single phase (a-phase) face-centered cubic (FCC) to a combination of a-phase and hexagonal close-packed (HCP) e-phase. This combination of two structural phases results in grain refinement of deposited coatings.

Addition of $\mathrm{Co}^{2+}$ into the electrolyte also enhances transport and deposition of suspended nanoparticles. Transfer rate of nanoparticles through the bulk of the electrolyte is a function of electrophoretic forces existing between charged nanoparticles and the cathode surface which in turn is influenced by the quantity of adsorbed cations on the nanoparticle surfaces (zeta potential). Therefore, the amount and type of adsorbed cations determines the magnitude of electrophoretic force [51]. It was reported that deposition of nanoparticles was enhanced by addition of $\mathrm{Co}^{2+}$ into the electrolyte, and it can be suggested that zeta potential in $\mathrm{Co}^{2+}$ containing baths is much more positive, owing to $\mathrm{Co}^{2+}$ being much more easily adsorbed onto the surfaces of nanoparticles than $\mathrm{Ni}^{2+}$. As a result, the electrophoretic forces exerted on nanoparticles are more intense.

\subsection{Current Density}

Current density (CE) affects the current efficiency of the process. Current efficiency (\%) describes the ratio of electrochemical current density for a specific reaction to total applied current density. It illustrates the transfer efficiency of electrons to the electrochemical system. Current efficiency $(\eta)$ is calculated by factoring charge passed, weight of deposits given by the difference between the weight of samples before and after deposition, and the chemical composition of the coatings as shown in Equation (13) [52].

$$
\eta=\frac{W}{I t}\left(\sum \frac{\left(F g_{i} e_{i}\right)}{K N_{i}}\right) \times 100
$$

where $W$ is the weight of the deposit (g), I is the current passed (A), $t$ is the deposition time (h), $g_{i}$ is the weight fraction of the element in the binary alloy deposit, $e_{i}$ is the number of electrons transferred in the reduction of $1 \mathrm{~mol}$ atoms of that element, $N_{i}$ is the atomic weight of that element $(\mathrm{g} / \mathrm{mol}), F$ is the Faraday constant $(96,485.3 \mathrm{C} / \mathrm{mol})$ and $K$ is a unit conversion factor ( $3600 \mathrm{C} / \mathrm{A} \mathrm{h}$ ).

Grain size, microstructure, brightness, thickness distribution, composition, surface morphology, microhardness and tensile strength of PC electrodeposited Ni-Co alloys are significantly influenced by variation of peak current density $J_{p}[34,53]$. It has been reported that current density has a significant influence on rate of deposition, plating adherence and the quality of plating of $\mathrm{Ni}-\mathrm{Co}$ coatings. The deposition rate increases with increases in current density [54]. Li et al. [34] used a pulse technique to research the effect of varying pulse frequency in electrodeposition of nanocrystalline Ni-Co deposits. It was found that increase in peak current density resulted in a lower cobalt content, smaller grain size, higher tensile strength and a colony like morphology. A recommendation for a peak current 
density range of $100-200 \mathrm{~A} \cdot \mathrm{dm}^{-2}$ was suggested for grain sizes ranging from $15-20 \mathrm{~nm}$, a $7 \%-8 \%$ cobalt content, $590-600 \mathrm{~kg} \mathrm{~mm}^{-2}$ microhardness and 118-1200 MPa tensile strength. When using the $\mathrm{PC}$ technique to electrodeposit $\mathrm{Ni}-\mathrm{Co}$, it was reported that the lowest current densities achieved the most compact layer of alloys [5].

Extremely high current density $J_{p}$ however has been reported to have a drastic effect on microhardness and tensile strength of electrodeposited Ni-Co coatings [34]. This has also held true for Ni-Co alloys electrodeposited using jet electrodeposition technique [4]. It could be suggested that this is because of the decrease in cobalt content with increase in the current density. Li et al. [34] researched the effects of peak current density on mechanical properties of $\mathrm{Ni}-\mathrm{Co}$ alloys and reported that $\mathrm{Co}$ content decreased with peak current density increase. One of the key aspects in electrodeposited $\mathrm{Ni}-\mathrm{Co}$ alloys and nanocomposite coatings is solid solution strengthening where the $\mathrm{Ni}$ and $\mathrm{Co}$ in electrolyte combine to form a solid solution. A decrease in Co content will therefore yield less solid solution strengthening for coatings electrodeposited at higher current densities. Figure 3 shows the relationship between peak current density and cobalt content [34].

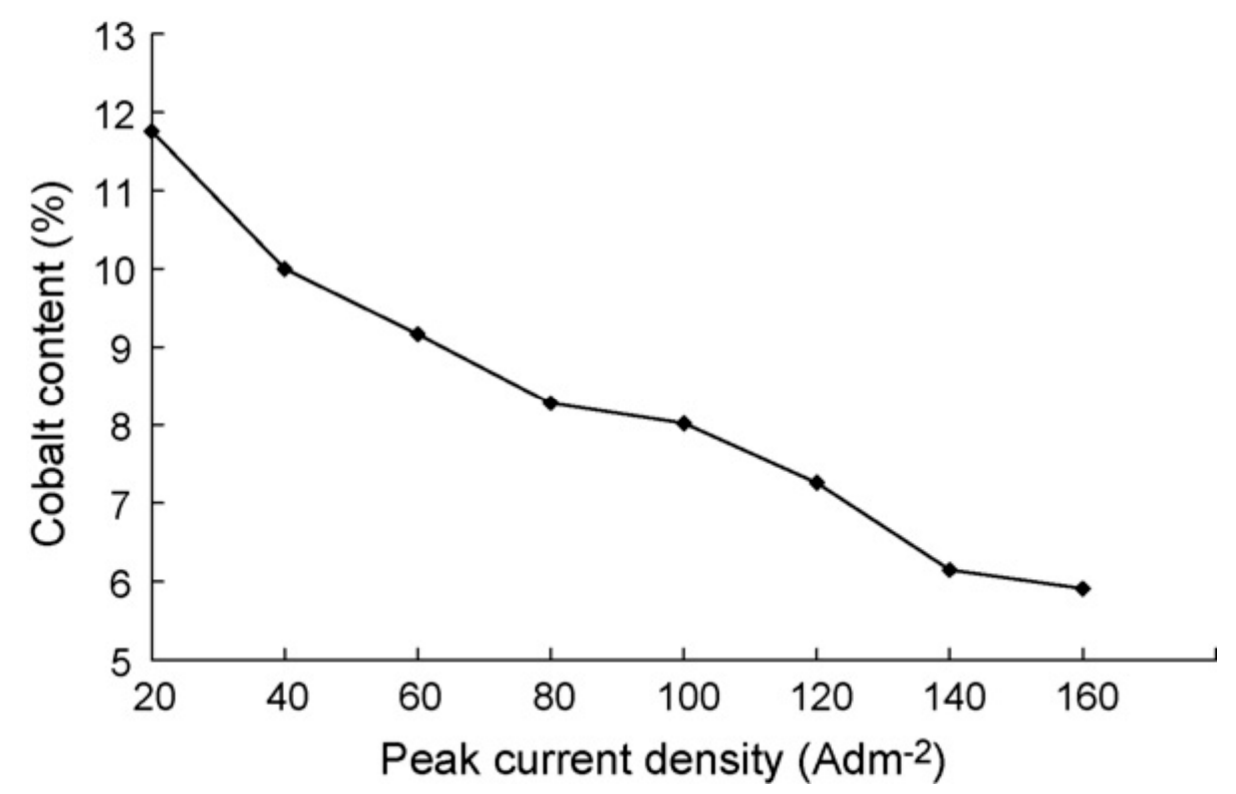

Figure 3. Cobalt content in Ni-Co alloy coatings with varying peak current density [34]. Reprinted from Applied Surface Science, 254, Yundong Li, Hui Jiang, Weihua Huang, Hui Tian, Effects of peak current density on the mechanical properties of nanocrystalline Ni-Co alloys produced by pulse electrodeposition/Pages No. 6865-6869, Copyright (2020), with permission from Elsevier.

In the case of $\mathrm{Ni}-\mathrm{Co}$, electrodeposition of the Co element is influenced and controlled by diffusion as compared to that of $\mathrm{Ni}$ which is predominantly controlled by activation. In light of this, an increase in cathodic current density results in an increase in cathodic overpotential. Concurrently, activation of the electrode reaction increases and, as a result, the rate of deposition of Ni element into the coating increases significantly [34].

In the case of $\mathrm{Ni}$-Co nanocomposites, it has been reported that thinner coatings resulting from smaller amounts of electricity tend to have a higher content of nanoparticles compared to thicker coatings that are formed with larger amounts of electricity. This suggests that nanoparticles become adsorbed during the early phase of deposition and become unevenly distributed with increases in thickness of coatings [55].

\subsection{Particle Content}

The magnetic properties, corrosion resistance, and mechanical properties of electrodeposited $\mathrm{Ni}-\mathrm{Co}$ nanocomposites are mostly governed by the amount and distribution of nanoparticles. There 
are several interrelated factors that influence incorporation and distribution of nanoparticles into the Ni-Co coatings. These factors can be broadly classified as (i) electrolyte composition (reagents, $\mathrm{pH}$, additives); (ii) nanoparticle characteristics (size, shape, type); (iii) deposition parameters (current density, bath temperature, concentration of nanoparticles and rate of electrolyte agitation); (iv) cobalt content in the coating where the $\mathrm{Co}^{2+}$ cations that are adsorbed on the particle surface increase the incorporation of nano particles into the coating deposits, causing an increase in nanoparticle deposition with increase in cobalt content $[28,51,56]$; and (v) electrode orientation, which determines the incorporation efficiency of the nanoparticles. Increase in nano particle content on Ni-Co nano composite coatings can be improved by using the sediment deposition technique (SCD) as opposed to the conventional electrodeposition technique. In the SCD technique, the electrodes immersed in the electrolyte are placed horizontally and parallel to each other. As such, electrodeposition in this technique takes advantage of gravitational pull coupled with the electrophoresis force resulting in better incorporation of nano particles [30,49]. In conventional electrodeposition, only the electrophoresis force is utilized. Figure 4 shows the electrodeposition setups depending on electrode orientation in the electrolyte. Research shows that nanoparticle content in electrodeposited Ni-Co coatings increases steadily with increase in nanoparticle concentration to a given maximum value beyond which the nanoparticle content in the deposit decreases. This increase in nanoparticle content with increase in concentration can be attributed to increased transportation of the nanoparticles to the cathode surface where more and more nanoparticles can be engulfed in the growing Ni-Co matrix. At high concentrations of nanoparticles, the interaction equilibrium between the suspended nanoparticles and the embedded ones is exceeded, beyond which the surface of the cathode becomes covered such that more suspended nanoparticles cannot be embedded into the coatings. Moreover, there is increased mechanical collisions between the nanoparticles and this reduces their transportation efficiency across the electrolyte bulk. The content of nanoparticles in the coatings therefore decreases.
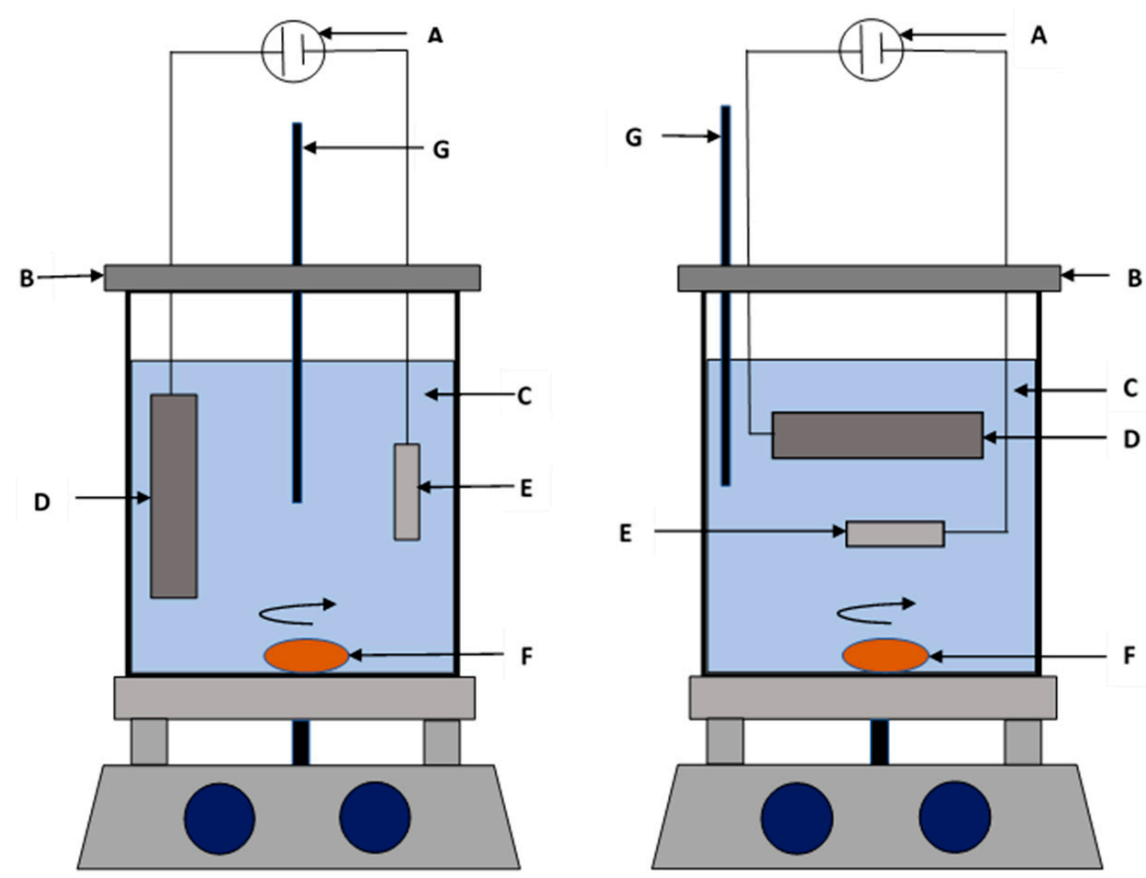

Figure 4. Schematic image of the deposition setups: (A) DC power supply, (B) Epoxy cover, (C) plating solution, (D) anode, (E) cathode, (F) magnetic bar and (G) external $\mathrm{pH}$-temperature probe [30].

\subsection{Electrolyte Agitation}

High electrodeposition current density translates to high deposition rates, which almost always causes burrs on the cathode surface as well as increasing the coating roughness. Electrolyte agitation causes a distinct reduction of burrs that are formed on the edges of coated substrates and this reduces 
the coating roughness and improves uniformity [53]. Furthermore, increasing the stirring speed of the electrolyte during the deposition process increases the content of nanoparticles deposited in the $\mathrm{Ni}-\mathrm{Co}$ coatings up to a given maximum level beyond which the content reduces $[26,57]$. At low agitation rates, the concentration of nanoparticles surrounding the cathode may reduce, resulting in the feed rate of the nanoparticles being lower than their adsorption into the Ni-Co matrix. Additionally, incomplete dispersion as a result of insufficient convection may cause agglomeration of nanoparticles and gravity settling. The surface energy of nanoparticles is greatly reduced when nanoparticles agglomerate, and this lowers the content in the deposited coatings. At higher agitation rates, the volume of nanoparticles reaching the cathode surface (mass transfer) increases thereby increasing the overall content of nanoparticles in the coatings. Goto et al. [55] reported that for the range of the experiment conducted, the nano diamond (ND) content in the coatings increased with increase in the stirring speed as shown in Figure 5. Where pulse electrodeposition is conducted using sediment deposition technique, agitation is a factor of $T_{O N} / T_{O F F}$ ratio, where $T_{O N}$ and $T_{O F F}$ represent the time intervals when the agitation is on and off. In this technique, the nanoparticles settle on the horizontal cathode with aid from gravitational force. As such, the lower the $T_{O N} / T_{O F F}$ ratio, the higher the rate of nanoparticle incorporation into the growing Ni-Co matrix [57].

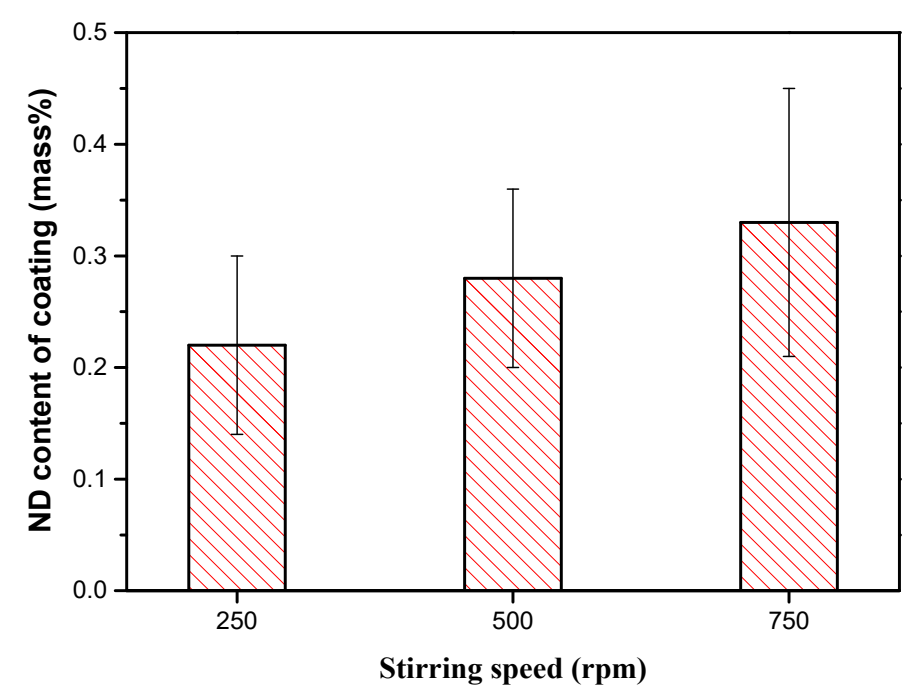

Figure 5. Relation between stirring speed and nano diamond (ND) content of the coatings [55].

Excessive rotation is however detrimental to coating quality. Vigorous hydrodynamic forces are generated at high agitation rates and these forces pluck out nanoparticles from the cathode surface before they become successfully embedded in the growing matrix surface, leading to lower nanoparticle content in the deposited coatings. This conclusion was reported by $[26,58,59]$ who related the increase in corrosion resistance up to a maximum value to an increase in electrolyte agitation rate, beyond which it decreased with further increase in agitation rate.

\subsection{Temperature}

Shi et al. [60] postulated that there is a two-fold effect with respect to temperature. When electrolyte temperatures are low, there is an increase in nanoparticle kinetic activity with a rise in the temperature of the bath, and this boosts adsorption of nanoparticles into the metal matrix. Increasing the temperature decreases the density and viscosity of the bath, thereby improving the mobility of ions within the electrolyte. As such, coatings deposited at higher temperatures exhibit superior properties owing to thicker coatings and higher nanoparticle contents than those deposited at lower temperatures [53].

Temperature variation has also been reported to alter the size of crystals in the deposited coatings. Prabu and Wang [53] reported that increasing temperature from 20 to $60{ }^{\circ} \mathrm{C}$ resulted in larger and 
sharper crystals. This was attributed to increase in rate of reducible ion diffusion to the cathode with an increase in temperature which decreased the polarization resistance. Research on the effect of temperature on $\mathrm{Ni}-\mathrm{Co}$ coatings shows that the deposition rate increases with increases in temperature of the electrolytic bath [4]. Idris et al. [54] reported that, for Ni-Co coatings electrodeposited using high speed jet electrodeposition, an increase in temperature from 55 to $65^{\circ} \mathrm{C}$ (at $1 \mathrm{~A} / \mathrm{cm}^{2}$ current density) resulted in a subsequent increase in thickness of the electrodeposited coatings from 61.4 to $71.7 \mu \mathrm{m}$, respectively. Similar increasing trends of the thickness with rise in temperature were observed at current densities of $0.1,0.3$ and $0.5 \mathrm{~A} / \mathrm{cm}^{2}$. This can be attributed to grain growth as a result of a free growth mode of Ni resulting from the temperature rise.

When the temperature exceeds certain limits, thermodynamic ion movement is enhanced greatly, and the nanoparticle's kinetic energy increases. As a result, less nanoparticles become adsorbed into the metal matrix. This conforms to Langmuir's adsorption theory, where temperature increase beyond certain levels has a negative effect on nanoparticle absorbability. As a result, the electric field and the overpotential of the cathode are decreased, making it harder for nanoparticles to be embedded into the coating. As such, lower contents of nanoparticles are observed in the deposited coatings.

\subsection{Electrolyte $p H$}

According to past research, it can be seen that the composition and structures of Ni-Co alloys and their nanocomposites can significantly affect their physiochemical properties. The effect of $\mathrm{pH}$ on Ni-Co deposits is predominantly dominated by three factors [61]: (i) the acidic environment in the electrolyte dissolving newly deposited metal atoms on the cathode surface, (ii) metal hydroxide formation and adsorption on the surface of the electrode, and (iii) normal electrodeposition of metals. When the electrolyte $\mathrm{pH}$ is low, the newly deposited metal becomes dissolved at a faster rate and formation and adsorption of metal hydroxides becomes depressed. In this case, the electrodeposition process is mainly dominated by normal electrodeposition of metals and this results in lower $\mathrm{Co}^{2+}$ in the bath. At higher $\mathrm{pH}$ values however, the formation and adsorption of metallic hydroxides is promoted, and the newly deposited metal dissolution becomes suppressed. For higher $\mathrm{pH}$ values, the electrodeposition process is dominated by formation and adsorption of Co hydroxides on the cathode surface and this produces higher Co contents in deposited coatings [62,63]. Tian et al. [61] reported a gradual increase in Co content from 9.4\% to 19.6\% with an increase in the value of $\mathrm{pH}$ from 2.0 to 5.4 . $\mathrm{pH}$ value in the electrolyte has also been observed to affect current efficiency. An increase in current efficiency from $52.1 \%$ to $81.2 \%$ was also reported with increase in $\mathrm{pH}$ from 2.0 to 5.4. Research linking $\mathrm{pH}$ value to hydrogen evolution has also been reported. Increase in $\mathrm{pH}$ in $\mathrm{Ni}-\mathrm{Co}$-based deposits has been associated with an increase the in hydrogen evolution rate, followed by creation of trace amounts of $\mathrm{Ni}$ and $\mathrm{Co}$ hydroxides which hinder the growth of crystals [64].

\subsection{Pulse Frequency}

Increased pulse frequency has been reported to achieve good Ni-Co films with smooth surface morphology and high microhardness, as well as better corrosion resistance of deposited coatings [5,37]. Pulse frequency has a significant influence on the morphology of the deposited coatings as well as the content of nanoparticles. At higher pulse frequencies, smaller grain sizes are obtained. Bigger grains tend to be more thermodynamically stable than smaller ones, and as such, an increase in OFF-time causes the grain size to increase [65]. Similar findings were reported by Yang and Cheng [32]. This was attributed to enhancement of the nucleation process by the $\mathrm{SiC}$ nanoparticles by providing electro crystallization nucleation sites and retarding crystal growth. Furthermore, the content of $\mathrm{SiC}$ in the $\mathrm{Ni}-\mathrm{Co} / \mathrm{SiC}$ nanocomposites increased with increasing pulse frequency. When pulse frequency levels are higher, the overpotential generated is much higher, and this provides more energy for nanoparticle adsorption into the coatings. As such, it can be concluded that higher pulse frequency offers better properties for deposited coatings as a factor of increased nanoparticle content. 


\subsection{Duty Cycle}

When low duty cycles are used, the resulting coating is characterized by finer and more compact structures than if higher duty cycles had been used. It has been reported that a low duty cycle increases the microhardness and corrosion resistance of electrodeposited $\mathrm{Ni}-\mathrm{Co} / \mathrm{SiC}$ nanocomposite coatings. This can be related to the increase in $\mathrm{SiC}$ nanoparticle content in the coatings at lower duty cycles [32]. With the increase in duty cycle, there is a transformation of the surface morphology from a branched, acicular structure to a more nodular structure. It can therefore be concluded that lower duty cycles offer the best properties for deposited materials.

\section{Mechanism of Ni-Co-Nanoparticle Electrodeposition}

The process starts with complete combination of $\mathrm{Ni}$ and $\mathrm{Co}$ in the electrolyte to form a solid solution [66]. At the same time, the surfaces of nanoparticles suspended in the electrolyte adsorb positive and negative ions (particle charging). The nanoparticles are then transferred by electrophoresis force and gravitational force to the growing $\mathrm{Ni}-\mathrm{Co}$ matrix where they become embedded into the deposit. Ni-Co deposition is believed to be anomalous deposition where the content of the less noble element (Cobalt in this case) is much higher than the concentration of the same element ions in the electrolyte $[16,67,68]$. This could be attributed to the relatively fast kinetics related to cobalt deposition. Moreover, the inhibition of nickel deposition in presence of cobalt ions is less likely as a result of evolution of metal hydroxides [67]. Figure 6 shows the cobalt content in deposited Ni-Co coatings as a function of Co concentration in the electrolyte [16].

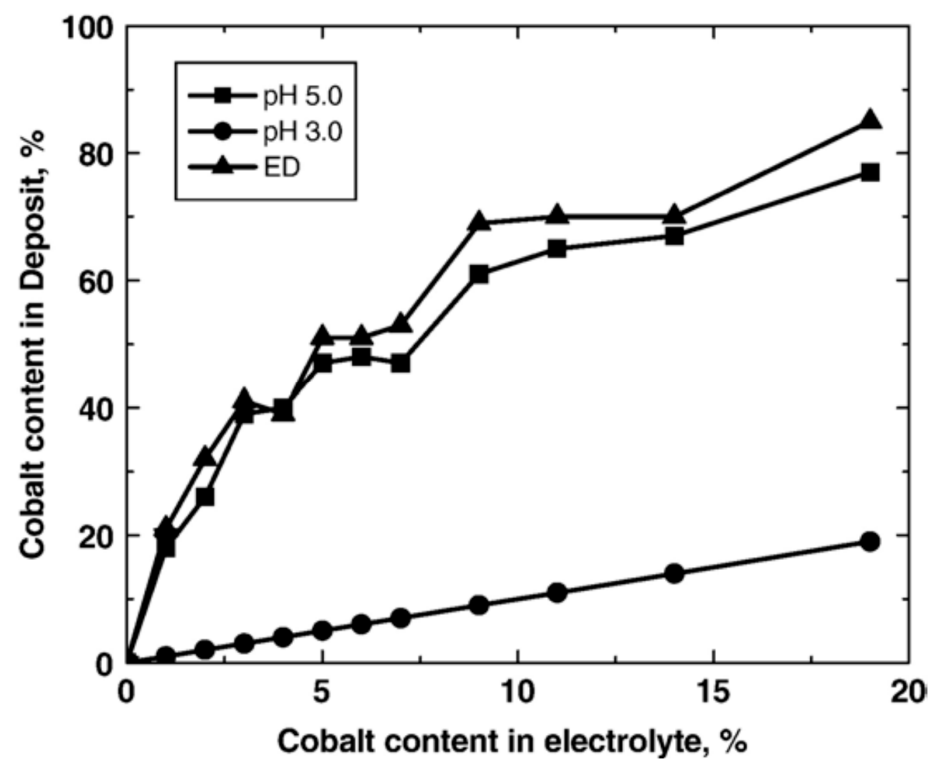

Figure 6. Alloy composition as a function of $\mathrm{Co}^{2+}$ concentration in the electrolyte [16]. Reprinted from Surface and Coatings Technology, 201, Meenu Srivastava, V. Ezhil Selvi, V.K. William Grips, K.S. Rajam, Corrosion resistance and microstructure of electrodeposited nickel-cobalt alloy coatings/Pages No. 3051-3060, Copyright (2020), with permission from Elsevier.

Many models have been proposed concerning co-deposition of nanoparticles. Celis [69] suggested that it was a five-step process which took into consideration the creation of an ionic cloud that engulfed the nanoparticles, movement of the nanoparticles through the electrolyte and the diffusion layer. These steps can be classified as: (i) formation of an ionic cloud on the surface of the nanoparticles from the adsorbed ions; (ii) the charged nanoparticles are then transferred through the electrolyte bulk until they reach the hydrodynamic boundary layer; (iii) through diffusion, the nanoparticles are transferred en-masse to electrode surface; (iv) adsorption of electroactive ions and the free ions occurs on the particles on the cathode; and (v) electroreduction of adsorbed ions occurs followed by incorporation 
of particles into the growing metal matrix [70]. Guglielmi's model proposed that the adsorption mechanism onto the cathode followed a two-step process for the charged nanoparticles. Firstly, the charged nanoparticles are loosely adsorbed while still being engulfed in a film of adsorbed cations [69].

\section{Baths Used in Electrodeposition Process for Ni-Co Coating}

$\mathrm{Ni}-\mathrm{Co}$ alloys have been synthesized using many different electrodeposition techniques: jet, direct current and Pulse current electrodeposition techniques [5]. With the said techniques, researchers have also used different types of electrolyte baths during electrodeposition such as sulfate, sulfamate, and chloride solutions $[21,22,71]$.

\subsection{Chloride Baths}

Many researchers over the years have used chloride baths to electrodeposit Ni-Co alloys and nanocomposites. Nickel chloride added to the chloride baths provides $\mathrm{Cl}^{-}$ions which are essential for efficient dissolution of the nickel anode [72]. Fan and Piron [67] studied anomalous electrodeposition of $\mathrm{Ni}-\mathrm{Co}$ alloy on $\mathrm{Cu}$ substrates using complex citrate and simple chloride baths. It was reported that the Ni-Co electrodeposited using the chloride baths exhibited anomalous deposition where the content of Co was higher than in the complex citrate bath. This was attributed to preferential deposition of Co which was more reactive (less noble) than $\mathrm{Ni}$. It was also found that simple chloride baths were better suited at electrodepositing at current densities as low as $0.1 \mathrm{~mA} \cdot \mathrm{cm}^{-2}$.

\subsection{Sulfate Baths}

Sulfate-based baths offer good electrodeposition prospects owing to their relative affordability compared to other baths and their ability to deposit high Co content coatings [64]. These baths contain both sulfate compounds as well as Ni chloride. The Ni chloride acts an additional source of $\mathrm{Ni}^{2+}$ ions in the electrolyte and this influences the thickness of the deposited coatings. The $\mathrm{Cl}^{-}$ions from the Ni chloride increases conductivity of the electrolyte solution by causing dissolution of $\mathrm{Ni}$ anodes $[72,73]$. Internal stresses in deposited coatings have been observed to decrease where chlorides are absent in electrolytes. Absence of $\mathrm{Cl}^{-}$ions is favorable in processes where the consumable anodes remain unused. However, they are used together with other reactive agents where the anodes are consumed during the electrodeposition process $[74,75]$.

\subsection{Sulphamate Baths}

Sulphamate and sulphamate-sulfate baths have been reported to deposit qualified and coherent $\mathrm{Ni}$-Co structures [68]. For the case of high-speed electrodeposition, nickel sulphamate baths containing boric acid have been preferred over watts baths because of the ease of obtaining relatively thicker coatings with less internal tensile stresses [76]. Ni-Co coatings deposited from sulfamate-sulfate baths have been reported to have smoother and finer surfaces and this can be attributed to lower stresses being generated in coatings deposited with these baths [68].

\section{Additives}

Additives are added into the electrolyte bath during electrodeposition to increase the range of current density, change physical and mechanical properties, reduce the size of crystallites by reducing growth, increase the coating's luster, reduce nanoparticle agglomeration, and reduce internal stresses generated during the deposition process [35].

\subsection{Boric Acid}

In 1916, Watts O.P. formulated and optimized an electrolyte comprising of nickel sulfate, nickel chloride and boric acid. This formula commonly known as Watts solution has been used extensively in nickel electrodeposition and its developmental impacts cannot be overstated [72]. The effect of boric 
acid in Nickel plating baths during electrodeposition has been researched over the years and the results can be summed up into six views:

(a) Boric acid suppresses oxygen evolution. Gadad and Harris [77] researched on oxygen incorporation in electrodeposited $\mathrm{Mi}, \mathrm{Fe}$ and $\mathrm{Ni}-\mathrm{Fe}$ alloy coatings. It was reported that an increase in applied current density resulted in an increase in the content of oxygen in Ni coatings and this posed a detrimental effect to the magnetic and electrical properties of the coatings. Addition of boric acid reduced the oxygen incorporation in all three electrodeposition systems, with less than $2 \mathrm{wt} \%$ oxygen observed in all cases. The buffering effect is not attributed directly to the boric acid but more to the complexing ability of boric acid with metal ions in the electrolyte.

(b) Boric acid promotes deposition of Nickel by acting as a catalyst. The adsorptive interaction of boric acid has also been observed in Ni-Zn alloy coatings where boric acid increased the current efficiency of the system at lower $\mathrm{Zn}$ (II) concentrations and increased the Ni content of the coatings at higher Zn (II) concentrations [78]. Significant change in primary nucleation rate coupled with suppressed secondary nucleation on coatings was also reported. Cyclic voltammetric deposition results have shown that the hydrogen evolution rate (HER) increases relative to the increase in boric acid concentration.

(c) Boric acid as a $\mathrm{pH}$ buffer. In electrodeposition, the practical buffer range is given at $\mathrm{pKa} \pm 1$, but this value is much higher in the case of boric acid $\left(9.23 \pm 1\right.$ at $\left.25^{\circ} \mathrm{C}\right)$. This is an anomaly considering the $\mathrm{pH}$ of the Ni electrolyte is 4.0. The anomaly can be attributed to formation of weak bound complexes between nickel ions and boric acid, such that the said complexes act as $\mathrm{pH}$ buffers $[79,80]$. The presence of these complexes however, has yet to be confirmed experimentally. This $\mathrm{pH}$ buffering phenomena has been found to be significantly influenced by the applied current density. Tsuru et al. [76] reported that at lower current densities (below $1.0 \mathrm{~A} \mathrm{dm}^{-2}$ ), the $\mathrm{pH}$ buffering properties of boric acid were exhibited.

(d) Suppression of hydrogen evolution by boric acid. During electrodeposition, electric current flowing through the system causes an increase in $\mathrm{pH}$ and as a result, hydrogen gas is produced at the cathode. Hydrogen evolution at the cathode is detrimental to the reduction of metal ions, and therefore boric acid is added into the plating bath solution to prevent electrode surface passivation as well as act as a surface agent which acts as a selective membrane to block passage of the reduction of Nickel, while permitting the reduction of iron in a retarded state. Improving the electrodeposition current density range thereby minimizes the effect [81]. Yin et al. [82] suggested that boric acid acted like a surfactant which was adsorbed onto the surface and hinders hydrogen evolution. The adsorbed boric acid interferes with the alloy nucleation process thereby reducing the hydrogen evolution rate in Ni-enriched phases [82]. It should be noted that the hydrogen evolution suppressing properties of boric acid have only been observed in presence of nickel ions and this suggests that there exists a mutual interaction between nickel and boric acid [76].

(e) Reduction of passive film formation by boric acid during Ni electrodeposition. Boric acid was found to significantly deter surface passivation on Ni reduction in Fe-Ni setups [82]. Tsuru et al. [76] suggested that, by acting as a surface agent, boric acid hindered passivation of the electrode surface during reduction of nickel.

(f) Accelerating growth rates of deposits. Boric acid improves the lateral as well as the outward growth rate during deposition of nickel [83].

It has also been reported that coatings electrodeposited in electrolytes containing boric acid exhibit better appearance coupled with reduced brittleness [81].

\subsection{Surfactants}

Nanoparticle stabilization in the electrolyte and non-agglomerated nanoparticle dispersion are key elements of producing Ni-Co nanocomposite coatings with excellent properties. Surfactants such as cetyltrimethylammonium bromide (CTAB) [84-86], sodium dodecyl sulfate (SDS) [87,88], and sodium 
lauryl sulfate (SLS) [89] are added into the Ni-Co nanocomposite coating baths to prevent nanoparticle agglomeration by reducing the electrolyte's surface tension to create smaller hydrogen bubbles thereby limiting pitting effect [35]. Surfactants of cationic and anionic nature are commonly used owing to their significant influence on ceramic-based nanoparticle dispersibility. Surfactants added into the bath work by changing the cathode polarization potentials, thereby changing the adhesion, smoothness, grain growth rate, and grain size of the deposited coatings [90]. Several researchers have used optimum quantities of different surfactants and reported improvement in corrosion resistance and mechanical properties [91].

Different surfactants have different effects on different nanoparticles. It was reported that CTAB surfactant offered a better alternative over SDS and triton $\mathrm{X}$ when they were compared in deposition of $\mathrm{SiC}$ nanoparticles using the PRC technique [92] and the PC technique [35]. However, the advantage offered by surfactant addition is not limitless. When the concentration of a surfactant exceeds a certain limit, it becomes counter-productive. Ger M [93] observed that excessive CTAB surfactant increased nanoparticle's adhesive force which resulted in deposition of coarser SiC nanoparticles.

\subsection{Saccharin}

Addition of saccharin results in an increase in alloy deposition overvoltage which promotes deposition of $\mathrm{Ni}$ while hindering that of $\mathrm{Co}$, and as such the resulting Ni-Co coatings exhibit reduced Co content $[4,94]$. Research shows that surface morphologies of Ni-Co coatings exhibited colony-like morphologies which consist of grain morphologies where several grain colonies converge to form one larger colony. As such, grain size is greatly reduced owing to the grain refinement phenomena. This is achieved by inhibition of pyramidal growth by saccharin thereby leading to the production of shiny, smooth surfaces [94]. This concurs with Weil and Cook [95] who reported that addition of organic additives such as coumarin and thiourea into the Ni-Co electrolytes hindered the growth of pyramids, caused surface roughness reduction, grain size reduction and increased surface brightness.

Increase in saccharin content in the coatings up to a certain value also improves the microhardness of Ni-Co coatings beyond which the microhardness reduces with increase in saccharin content. $\mathrm{Li}$ et al. [94] reported that increase in saccharin content to $3 \mathrm{~g} / \mathrm{L}, 4 \mathrm{~g} / \mathrm{L}$ and $5 \mathrm{~g} / \mathrm{L}$ resulted in increased microhardness values of $456 \mathrm{~kg} / \mathrm{mm}^{2}, 507 \mathrm{~kg} / \mathrm{mm}^{2}$ and $554 \mathrm{~kg} / \mathrm{mm}^{2}$, respectively. This conclusion was also reached by Wang et al. [96]. The increase in microhardness with increase in saccharin content to a certain value can be attributed to grain refining effect, and the decrease in microhardness beyond that level of saccharin can be attributed to the inverse Hall-Petch relationship when refining of grain size reaches a certain level [97]. The drawback to adding saccharin to the electrolyte is the reduced ductility of the resulting Ni-Co coatings owing to the sulphur and carbon impurities that are usually present in saccharin laden nanocrystalline coatings. The said impurities separate into grain boundaries thereby preventing the efficient sliding of grain boundaries and hence the low ductility [98].

Saccharin has been reported to act as an internal stress reliever in electrodeposited Ni-Co coatings and this has been attributed to grain refinement. Internal stresses are developed within the coating layer during the electrodeposition process and they cause oriented resultant strain in deposited coatings. Hydrogen ion reduction occurs at the cathode, and the small sized $\mathrm{H}^{+}$promote favorable conditions for diffusion to the coating's active centers. As the $\mathrm{H}^{+}$become transformed into $\mathrm{H}$ molecules, internal stresses are developed as the volume changes. They are classified into three main categories [99-102]:

(i) Macroscopic stresses. These are caused by inhomogeneity in the deposited coatings. These comprise of either compressive or tensile stresses and they occur in galvanic cells.

(ii) Microscopic stresses. These originate at grain boundaries and at locations where dislocations accumulate.

(iii) Sub-microscopic stresses.

While internal stresses have been known to improve hardness and abrasion resistance of deposited coatings, at high levels, these stresses increase the coating's brittleness. Brittle coatings develop 
extensive microcracks which expose the substrate surface to corrosive attack and degradation when exposed to a corrosive medium. The saccharin molecules are reversibly adsorbed on active sites thereby hindering growth of crystals and impeding surface diffusion of adatoms. As such the volume of grain boundaries increases and this dissipates the energy created by internal stresses [103].

Saccharin has been employed in tensile research of electrodeposited Ni-Co nanocomposite coatings. Wang et al. [96] reported that $\mathrm{PC}$ deposited $\mathrm{Ni}-\mathrm{Co} / \mathrm{Al}_{2} \mathrm{O}_{3}$ nanocomposites containing saccharin exhibited low-temperature superplasticity, where a maximum elongation of $632 \%$ was achieved at a strain of $1.67 \times 10^{-3} \mathrm{~s}^{-1}$ and a temperature of $823 \mathrm{~K}$. The dominant superplastic accommodation process was taken to be dislocation glide.

\section{Properties of Electrodeposited Ni-Co Coatings}

\subsection{Microstructure}

As stated earlier, $\mathrm{Ni}-\mathrm{Co}$ coatings deposition is anomalous. This can be explained as a function of local $\mathrm{pH}$ increase resulting in creation and adsorption of metallic hydroxides, as well as a faster rate of cobalt hydroxide adsorption [104], deposition of Co cations (first step) followed by Ni deposition (second step) in a two-step process [105], and preferential Co element deposition which causes the diffusion layer to become depleted [4]. Ni-Co alloys with up to $58 \mathrm{wt} \%$ cobalt content exhibit the single phase of Ni matrix with FCC type of phase structure. When the cobalt content is in the range between $64 \mathrm{wt} \%$ to $80 \mathrm{wt} \%$ the phase structure becomes a combination of FCC and HCP as shown in Figure 7 [68].

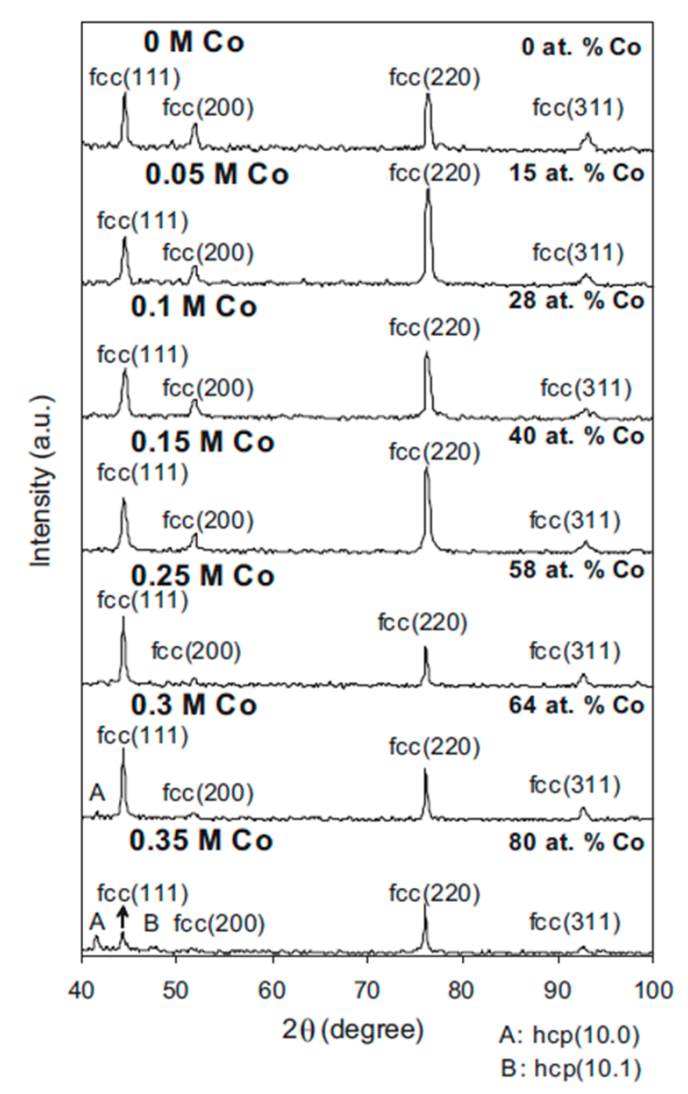

Figure 7. X-ray diffraction (XRD) patterns of Ni-Co films deposited from the electrolytes containing different Co concentrations [68]. Reprinted from Applied Surface Science, 258, Ali Karpuz, Hakan Kockar, Mursel Alper, Oznur Karaagac, Murside Haciismailoglu, Electrodeposited Ni-Co films from electrolytes with different Co contents/Pages No. 4005-4010, Copyright (2020), with permission from Elsevier. 
Ni-Co alloys with Co content above $80 \mathrm{wt} \%$ exhibit complete HCP phase structure $[16,40,68]$. $\mathrm{Ni}-\mathrm{Co}$ alloy surface morphologies are significantly influenced by the coating's chemical composition. Rafailovic et al. [106] researched the mechanical properties of $\mathrm{Ni}-\mathrm{Co}$ alloys deposited on $\mathrm{Cu}$ substrates. It was reported that a platelet structured morphology was formed for coatings with a $\mathrm{Ni}^{2+} / \mathrm{Co}^{2+}$ ratio of 0.25 at $65 \mathrm{~mA} \mathrm{~cm}^{-2}$. The surface morphology exhibited enhanced dendritic growth when the ratios were 0.5 and 2. At the highest $\mathrm{Ni}^{2+} / \mathrm{Co}^{2+}$ ratio of 4 , the surface morphology exhibited cauliflower structure as shown in Figure 8.

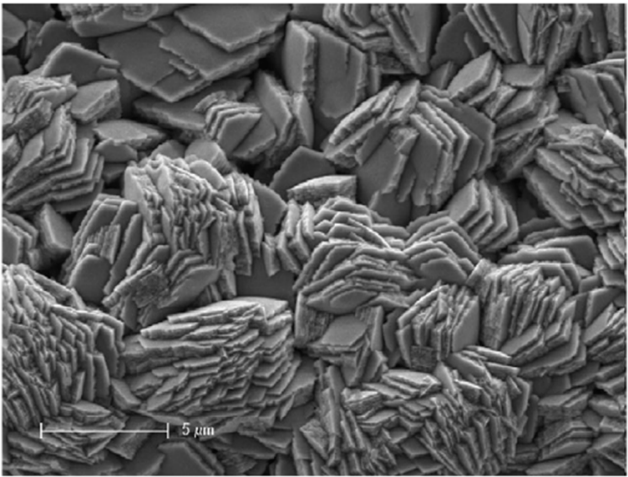

(a)

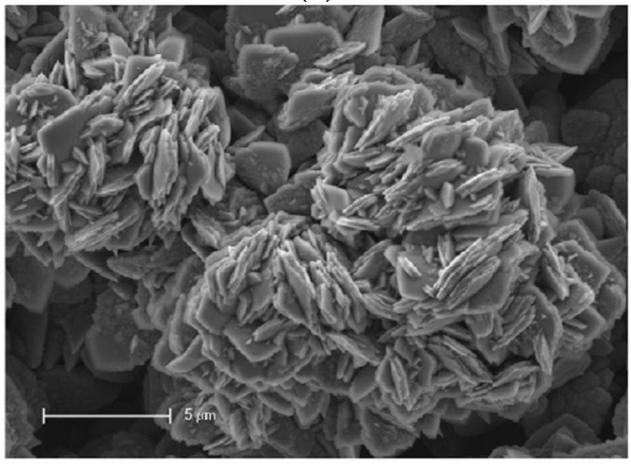

(c)

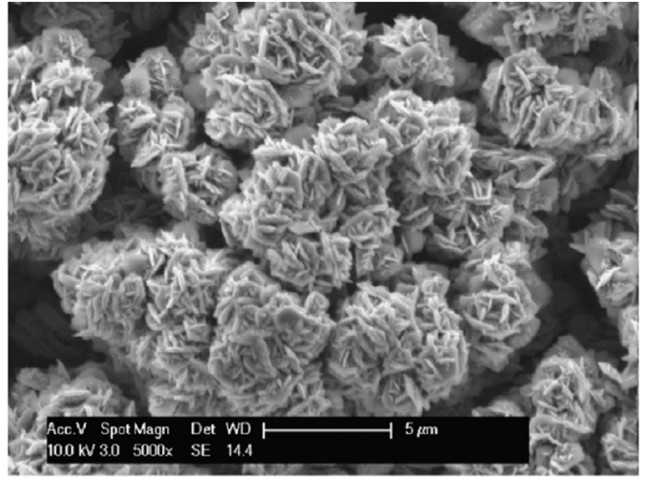

(b)

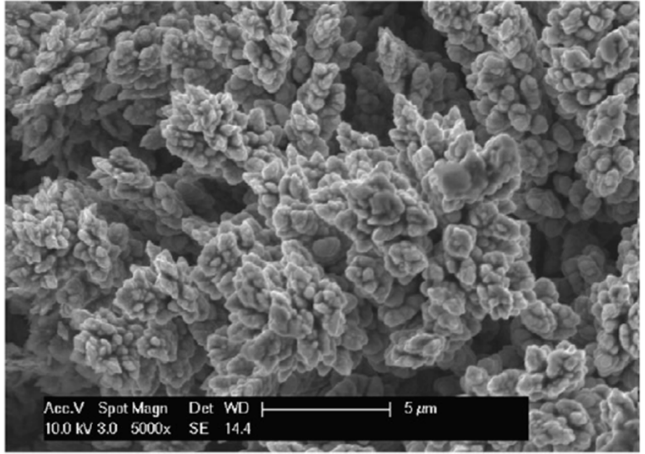

(d)

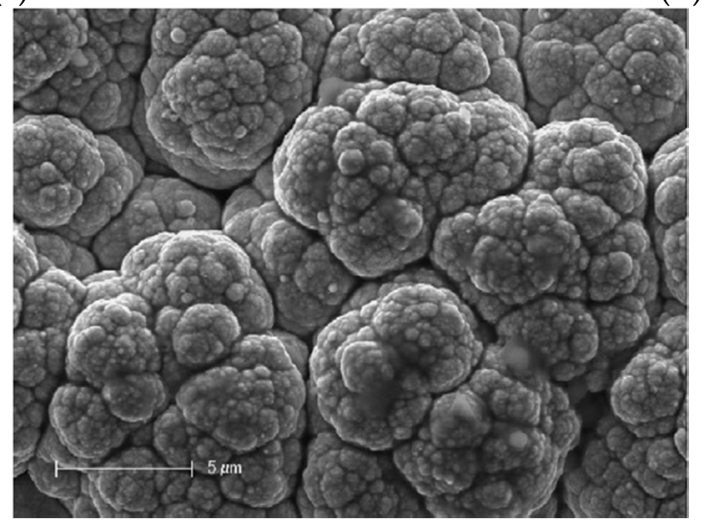

(e)

Figure 8. SEM micrographs of Ni-Co deposits obtained at a current density $65 \mathrm{~mA} \mathrm{~cm} \mathrm{cr}^{-2}$ from an electrolyte with different $\mathrm{Ni}^{2+} / \mathrm{Co}^{2+}$ concentration ratio: (a) 0.25 , (b) 0.5 , (c) 1, (d) 2 and (e) 4 [106]. Reprinted from Materials Chemistry and Physics, 120, L.D. Rafailovic, H.P. Karnthaler, T. Trisovic, D.M. Minic, Microstructure and mechanical properties of disperse Ni-Co alloys electrodeposited on $\mathrm{Cu}$ substrates/Pages No. 409-416, Copyright (2020), with permission from Elsevier.

The microstructure of electrodeposited Ni-Co-based coatings is affected by evolution of hydrogen gas at the cathode. Hydrogen is a by-product of the electrodeposition process owing to the breakdown of water molecules in the plating solution during the electrodeposition process. This holds both an 
advantageous and detrimental effect depending on the desired output of the process. Hydrogen offers a promising versatile, efficient, and clean candidate for use as an energy source to replace commonly used fossil fuels which cause $\mathrm{CO}_{2}$ emissions that are harmful to the environment [107-109]. Hydrogen can be successfully generated using the less efficient (higher operating cost) alkaline water electrolysis [110,111], or using low hydrogen evolution reaction (HER) overpotential electrodes [112]. Ni-based alloys and compounds form such electrode materials owing to their low cost coupled with high catalytic activity and stability [113]. In the case of depositing quality coatings however, the evolution of hydrogen gas is detrimental to the structure, hence the critical need to control its production. The synthesized hydrogen gas attaches to the surface of the base metal creating a blanket of air that inhibits nucleation and deposition of the coatings and this causes poor adherence leading to non-uniform coatings [114]. The hydrogen evolution phenomenon has been reported to be more significant at higher current densities, owing to lower hydrogen overpotential where numerous gas pits are formed on the coating surface as a result of the hydrogen produced [112].

\subsection{Mechanical Properties}

Microhardness in electrodeposited Ni-Co coatings increases with an increase in Co content in the coatings. Baghal et al. [115] reported similar findings when the microhardness of Ni-SiC coatings was compared to $\mathrm{Ni}-\mathrm{Co} / \mathrm{SiC}$ coatings as a function of increasing current density, as shown in Figure 9.

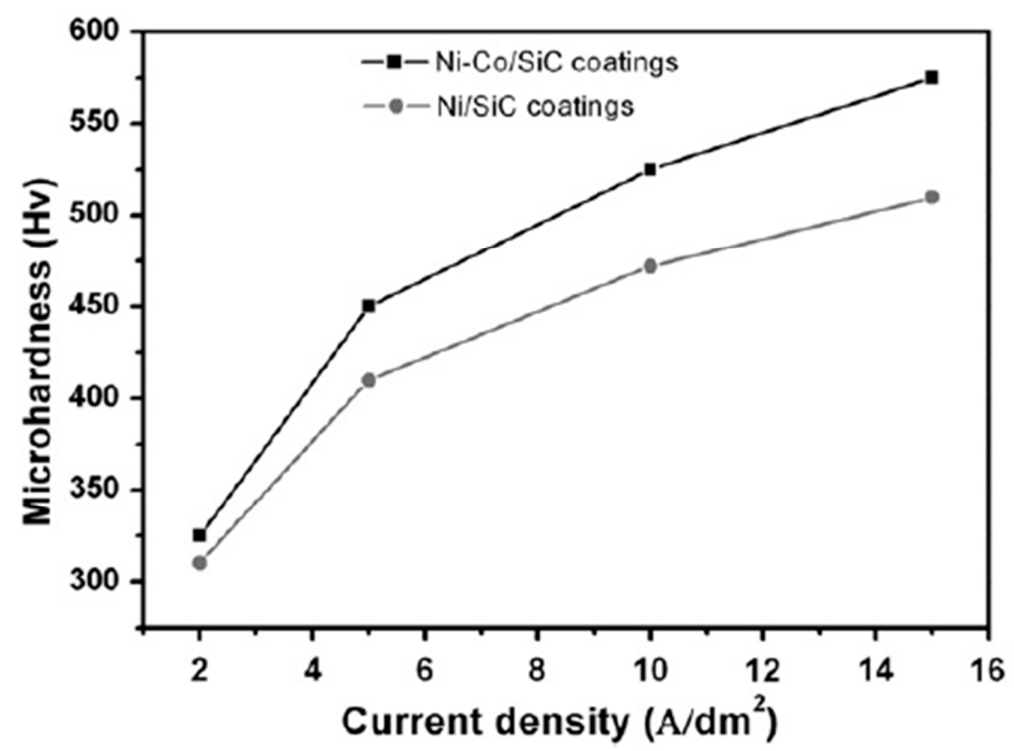

Figure 9. The effect of current density on microhardness of $\mathrm{Ni}-\mathrm{Co} / \mathrm{SiC}$ and $\mathrm{Ni} / \mathrm{SiC}$ coatings [115]. Reprinted from Surface and Coatings Technology, 206, S.M. Lari Baghal, M. Heydarzadeh Sohi, A. Amadeh, A functionally gradient nano-Ni-Co/SiC composite coating on aluminum and its tribological properties/Pages No. 4032-4039, Copyright (2020), with permission from Elsevier.

Enhancement of micro-hardness in Ni-Co alloy coatings as a function of Co content can be linked to the (i) grain size reduction, (ii) phase composition, where two-phase structures are formed, and (iii) solid solution strengthening $[16,20,116]$. Babak [12] reported similar observations where coatings up to $45 \mathrm{wt} . \%$ Co were characterized solely by FCC lattices. No other phase was observed from the XRD pictographs and it was suggested, therefore, that the effect of phase composition on microhardness of the said coatings was not significant. This was held as evidence that solid solution hardening played a key role in the microhardness of the deposited Ni-Co coatings. The grain size of deposited Ni-Co alloy coatings decreased gradually with increase in content of Co element in the coatings [12].

The wear rate of deposited Ni-Co coatings has been observed to decrease with increase in Co content in the deposits. The phenomena can be associated with increase in microhardness with increase in Co content. A relationship exists between wear rate and microhardness of a coating, called Archard's 
law, which provides that the sliding wear volume loss is directly proportional to friction coefficient and inversely proportional to the hardness of the material [117]. This relationship can be seen in Figure 10 [60].

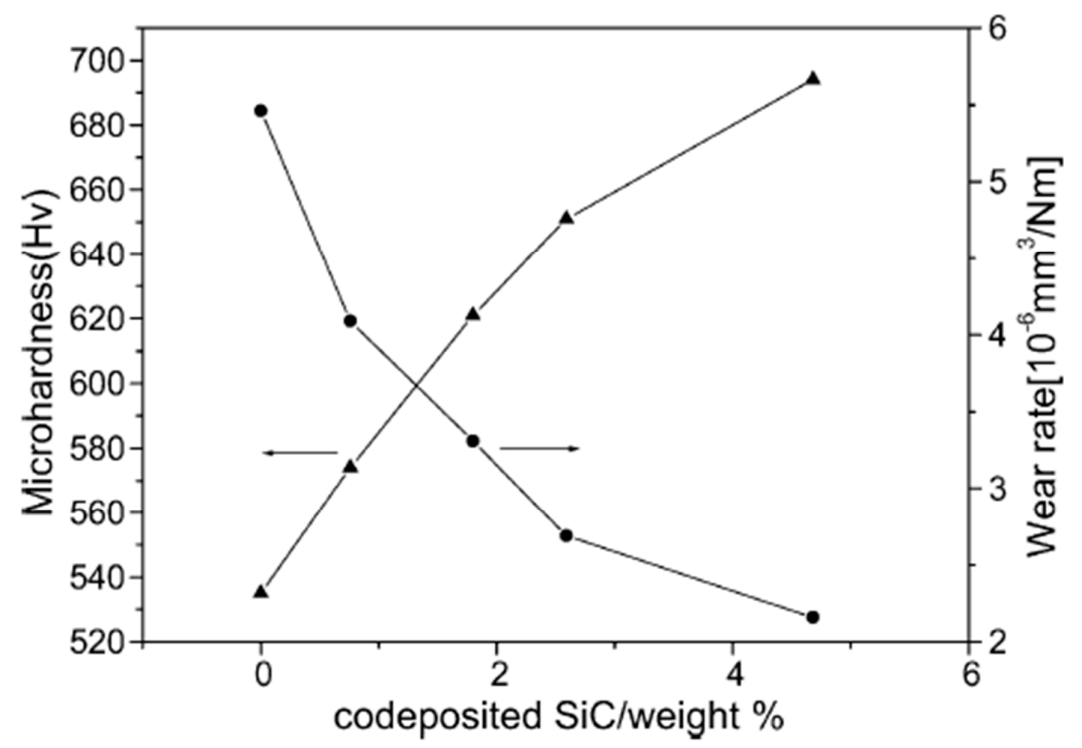

Figure 10. Microhardness and wear rate of the nanocomposite coating vs. weight percentage of co-deposited $\mathrm{SiC}$ particulates in the nanocomposite coating [60]. Reprinted from Applied Surface Science, 252, Lei Shi, Chufeng Sun, Ping Gao, Feng Zhou, Weimin Liu, Mechanical properties and wear and corrosion resistance of electrodeposited Ni-Co/SiC nanocomposite coating/Pages No. 3591-3599, Copyright (2020), with permission from Elsevier.

In some instances, however, the wear rate decreases with decrease in microhardness, a deviation from Archard's Law. This is concurrent with findings reported by Wang et al. [20] where the decrease in wear rate beyond $49 \mathrm{wt} \%$ with a concurrent decrease in microhardness from $462 \mathrm{HV}$ to $298 \mathrm{HV}$ was attributed to changes in the phase structure. As Co content increases, the phase structure of the deposited Ni-Co coatings changes from solely FCC structure, to FCC coupled with HCP structure, and when the Co content goes beyond $80 \mathrm{wt} \%$ (See Figure 7), the phase structure is transformed to a predominantly $\mathrm{HCP}$ structure. This transformation in phase structure to a higher ratio of $\mathrm{HCP}$ causes a decrease in the coefficient of friction (COF) of the deposited Co-rich coatings and therefore decreased wear loss [20]. As such, the decreasing wear rate was associated with the decreasing coefficient of friction (COF). This is shown in Figure 11.

Magnetic measurements done on electrodeposited Ni-Co coatings show that Co content has significant influence on the magnetic and structural properties of the coatings. Increase in Co content in the coatings results in a gradual increase in the saturation magnetization. This conclusion is concurrent with Karpuz et al. [68] where the highest in-plane saturation magnetization of $1000 \mathrm{emu} / \mathrm{cm}^{3}$ was achieved at the highest contents of $\mathrm{Co}(80 \%)$. The same trend was also reported by [118].

Coatings improve the performance of the component by isolating the material's structure from the environment. Different substrate materials have been used for deposition of $\mathrm{Ni}, \mathrm{Ni}-\mathrm{Co}$, and $\mathrm{Ni}-\mathrm{Co}$-nanocomposite based coatings ranging from steel, aluminum, to copper $[106,115]$. Failure of systems is usually associated with substrate-coating interface failure owing to the differences in mechanical and physical properties. Coating adhesion plays a key role in a surface's wear resistance and it is measured through friction testing where the friction abruptly changes when the coating breaks, also known as the critical load point. As such, a larger critical load indicates stronger coating adhesion [119]. Different mechanisms aimed at improving the critical load have been researched over the years. Wei et al. [120] reported that use of the magnetic jet electrodeposition technique (MJE) yielded a higher adhesion compared to traditional jet electrodeposition technique (TJE). At $4 \mathrm{~g} / \mathrm{L}$, TJE 
technique had a maximum adhesion of $23.58 \mathrm{~N}$ compared to $33.20 \mathrm{~N}$ under MJE technique as shown in Figure 12.

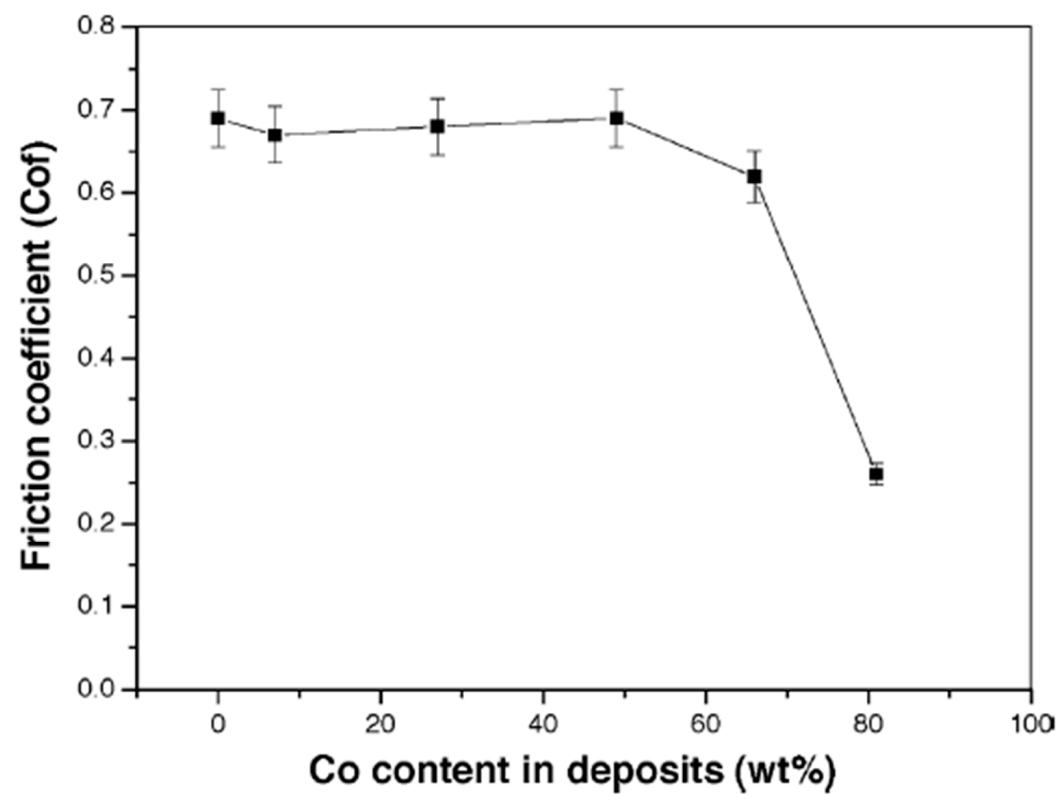

Figure 11. Friction coefficient as function of Co content in the Ni-Co alloy deposit [20]. Reprinted from Applied Surface Science, 242, Liping Wang, Yan Gao, Qunji Xue, Huiwen Liu, Tao Xu, Microstructure and tribological properties of electrodeposited Ni-Co alloy deposits/Pages No. 326-332, Copyright (2020), with permission from Elsevier.

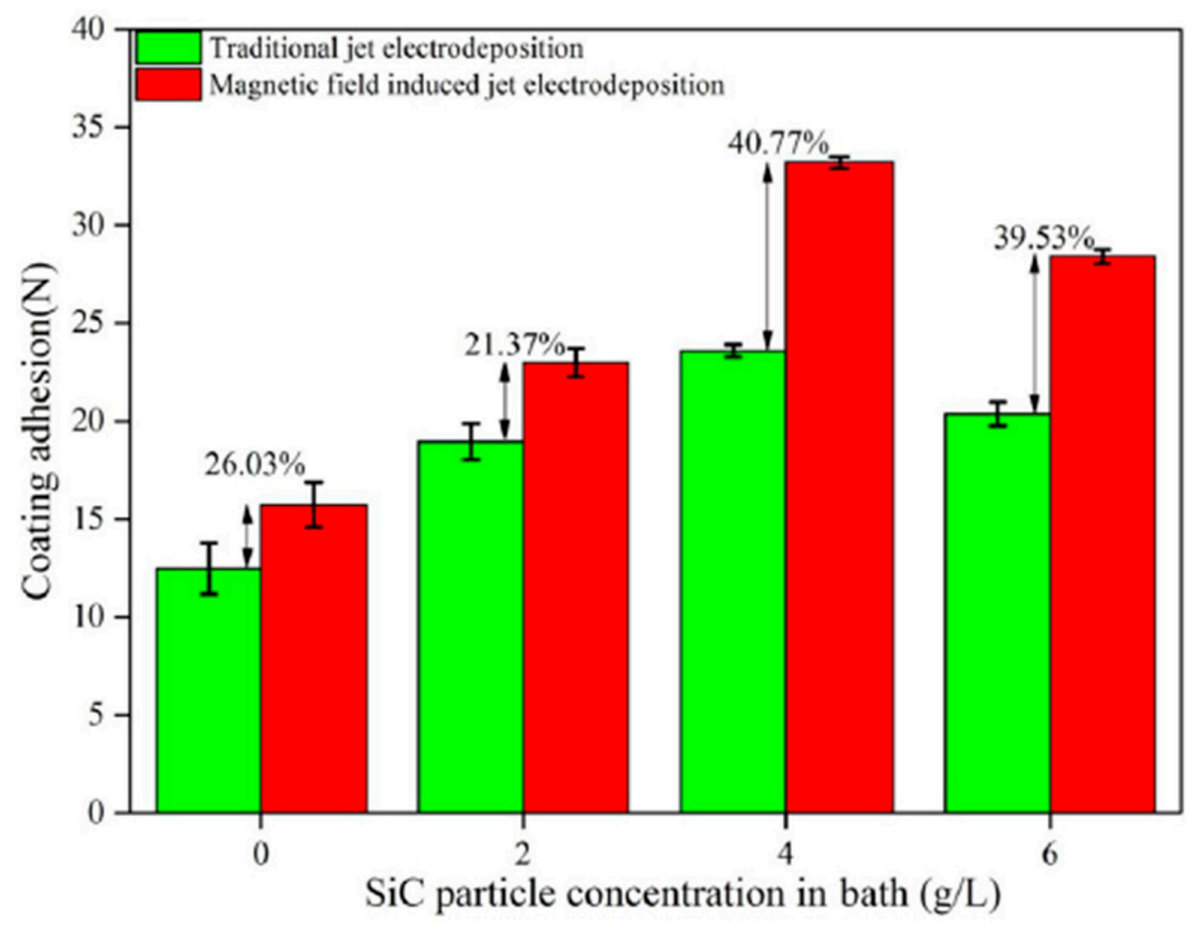

Figure 12. Adhesion of the composite coatings [120]. Reprinted from Journal of Alloys and Compounds, 791, Wei Jiang, Lida Shen, Mingyang Xu, Zhanwen Wang, Zongjun Tian, Mechanical properties and corrosion resistance of $\mathrm{Ni}-\mathrm{Co}-\mathrm{SiC}$ composite coatings by magnetic field-induced jet electrodeposition/Pages No. 847-855, Copyright (2020), with permission from Elsevier. 
The adhesion of Ni-Co binary alloys can be further improved by incorporating nanoparticles into the matrix such that the effective area of contact between the substrate and coatings is increased, and the dispersion strengthening mechanism of the nanoparticles improves the coating's adhesion [121,122]. Another concept that has been considered for adhesion improvement is functionally graded materials (FGMs), whereby interfacial problems are mitigated by controlling progressive changes in structure and properties [123].

$\mathrm{Ni}$-Co-nanocomposite coatings deposited at high current densities have exhibited higher surface roughness. This can be traced to adsorption of nanoparticles into the coating surface coupled with formation of pits and crevices as a result of an increase in hydrogen evolution rate at high current densities. Similar observations were made by Dheeraj et al. [35] where a surface roughness of $2.31 \pm$ $1.78 \mu \mathrm{m}$ was reported for sample S3 which represented coatings deposited at higher current densities.

\subsection{Corrosion Behaviour}

The corrosion behavior of electrodeposited Ni-Co alloy can be attributed to: chemical composition, grain size, preferred orientation, and phase structure. In the case of chemical composition, it has been reported that formation of Ni-Co alloy can change the nobility of the materials thereby affecting corrosion resistance [124]. Co is less noble that $\mathrm{Ni}$, that is, it is more reactive compared to Ni. Therefore, increasing the Co content is bound to produce coatings with greater electrochemical activity than that of purely $\mathrm{Ni}$ coatings [125]. The polarization resistance of $\mathrm{Ni}-\mathrm{Co}$ alloys has been reported to increase with increase in Co content up to a given limiting value, beyond which the corrosion resistance decreases with further increase in Co content. This is concurrent with findings reported by Babak et al. [126] where $\mathrm{Ni}-17 \mathrm{Co}$ coatings exhibited better corrosion resistance $\left(10.08 \mathrm{k} \Omega \mathrm{cm}^{2}\right)$ compared to $\mathrm{Ni}-42 \mathrm{Co}$ alloy coatings $\left(3.32 \mathrm{k} \Omega \cdot \mathrm{cm}^{2}\right)$ as shown in Figure 13.

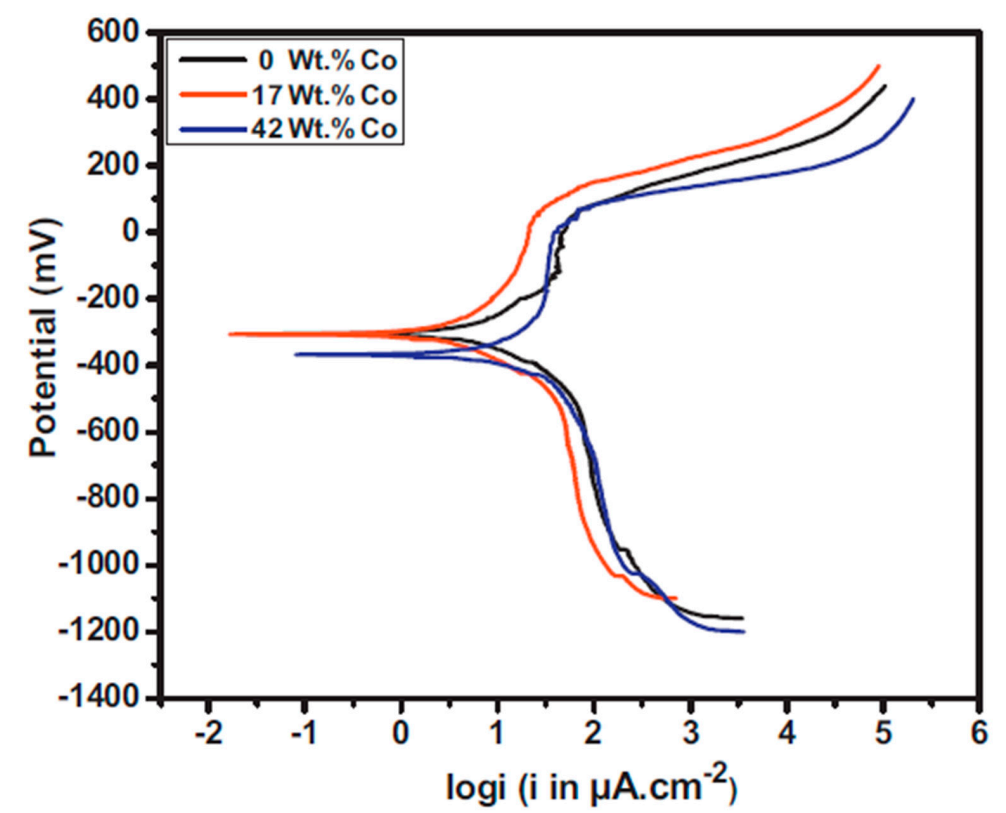

Figure 13. The potentiodynamic polarization curves of the Ni-Co alloy coating as a function of the cobalt content [126]. Reprinted from Applied Surface Science, 307, Babak Bakhit, Alireza Akbari, Farzad Nasirpouri, Mir Ghasem Hosseini, Corrosion resistance of $\mathrm{Ni}-\mathrm{Co}$ alloy and $\mathrm{Ni}-\mathrm{Co} / \mathrm{SiC}$ nanocomposite coatings electrodeposited by sediment codeposition technique/Pages No. 351-359, Copyright (2020), with permission from Elsevier.

The phase structures of Ni-Co binary alloy coatings have been observed to consist of FCC single-phase solid solutions [12,126]. In the case of the coating's materials microstructure, single phase structures have proven more corrosion resistant than two-phase structures. Corrosion attacks usually 
occur along grain boundaries (between phases) owing to the galvanic cells that are created between the phases and their higher levels of energy compared to parts located within the crystal itself. Moreover, base centered cubic (bcc) phases have lower corrosion resistance compared to face centered cubic (FCC) phases as a result of their lower packing factor.

As a factor of preferred orientation, it has been reported that $\mathrm{Zn}-\mathrm{Ni}$ alloys exhibit high corrosion resistance owing to crystallographic planes being predominantly present with higher packing densities [127]. Babak et al. reported that Ni-17Co alloy coatings exhibited high corrosion resistance as a function of predominantly (111) preferred orientation. Lupi et al. [66] found that electrodeposited $\mathrm{Ni}-\mathrm{Co}$ alloys containing $40 \%-50 \%$ Co content provide the best catalytic properties of the alloy for the reaction leading to evolution of hydrogen in alkaline media.

\section{NiCo-Ceramic Composites}

Nanoparticles have been added to the Ni-Co matrix to further improve the properties. Ni-Co nanocomposite coatings exhibit superior hardness and wear resistance to alloy coatings. This can be attributed to inherent hardness of nanoparticles used, coupled with nanoparticle strengthening through Orowan mechanism [30]. According to this mechanism, the adsorbed nanoparticles hinder the formation and propagation of dislocations as the metallic matrix carries the load.

In some instances, the increase in Co concentration in the bath has been reported to improve nanoparticle incorporation thereby improving coating properties such as corrosion resistance [30]. This effect of nanoparticles can be linked to several factors:

(i) Reduction of exposed area open to corrosive media. Nanoparticles used in Ni-Co nanocomposite electrodeposition are usually ceramics. When these nanoparticles are uniformly distributed in the Ni-Co matrix, they minimize the metallic area that is exposed to corrosive attacks and, as a result, the corrosion potential is shifted to nobler values [128].

(ii) $\mathrm{SiC}$ nanoparticles acting as physical barriers that hinder creation and propagation of corrosive pits.

(iii) Nanosized $\mathrm{SiC}$ particles which offer greater corrosion resistance than micro-sized particles when used to deposit $\mathrm{Ni}-\mathrm{Co} / \mathrm{SiC}$ nanocomposites. Owing to their smaller sizes, such nanoparticles can access structural defects such as porosities and cracks thereby mitigating the corrosive effect at such locations.

(iv) Formation of micro-galvanic cells. The metallic matrix acts as an anode while the nanoparticles act as cathodes when the $\mathrm{Ni}-\mathrm{Co}$ nanocomposite coatings are exposed to corrosive media. Where the metallic matrix's electrochemical potential is less positive than that of the nanoparticles, the corrosion mechanism of the micro-galvanic cells is transformed to uniform corrosion from pitting and localized corrosion [126].

Other factors that may be associated with metallic alloy nanocomposite coatings include: reinforcing phase induced hardening, texture evolution, grain refinement of the matrix, and solid solution strengthening depending on selected matrix [129-131]. Wear resistance of Ni-Co alloy coating is greatly improved by incorporation of nanoparticles in the matrix. This increase can be attributed to the dispersion strengthening effect of adsorbed hard nanoparticles coupled with grain-refining tendencies. The uniform dispersion in the matrix and to a small extent particle agglomeration may be linked to improved wear resistance in Ni-Co nanocomposites. Similar conclusions were reached by Shi et al. [60].

\subsection{Effect of $\mathrm{Al}_{2} \mathrm{O}_{3}$ Nanoparticles}

$\mathrm{Al}_{2} \mathrm{O}_{3}$ nanoparticles have inherent high corrosion resistance, and in the nano-scale range, can efficiently contribute to porosity reduction, thereby further boosting the corrosion resistance of deposited coatings [132,133]. Incorporation of $\mathrm{Al}_{2} \mathrm{O}_{3}$ nanoparticles into the $\mathrm{Ni}-\mathrm{Co}$ matrix produces nanocomposite coatings characterized by nodular, uniform, and compact morphology [26]. The content of $\mathrm{Al}_{2} \mathrm{O}_{3}$ in the coatings increases with increases in $\mathrm{Al}_{2} \mathrm{O}_{3}$ concentration in the electrolyte. The same 
trend was reported by Borkar [31], with a maximum $\mathrm{Al}_{2} \mathrm{O}_{3}$ content being achieved with $40 \mathrm{~g} \mathrm{~L}^{-1}$ nanoparticle concentration, beyond which the content decreased. Ni-Co alloy coatings exhibit a face centered cubic (FCC) crystal structure and the same has been reported for $\mathrm{Ni}-\mathrm{Co} / \mathrm{Al}_{2} \mathrm{O}_{3}$. However, the crystal orientation of the resulting $\mathrm{Ni}-\mathrm{Co} / \mathrm{Al}_{2} \mathrm{O}_{3}$ nanocomposite coating undergoes transformation from crystal face (200) lattice to (111) lattice [40].

Like with most $\mathrm{Ni}-\mathrm{Co}$ nanocomposite coatings, adsorption of $\mathrm{Al}_{2} \mathrm{O}_{3}$ nanoparticles into the $\mathrm{Ni}-\mathrm{Co}$ matrix results in a subsequent increase in the coating's hardness and wear to a certain maximum, beyond which the coating becomes brittle and spalls off. Tian [26] concluded that an increase in $\mathrm{Al}_{2} \mathrm{O}_{3}$ nanoparticle concentration in the bath caused a subsequent increase in the corrosion resistance of the $\mathrm{Ni}-\mathrm{Co} / \mathrm{Al}_{2} \mathrm{O}_{3}$ nanocomposite coatings up to a certain limiting value, suggesting that optimal operating conditions and parameters are key to corrosion resistance maximization. This may be attributed to uniform dispersion of $\mathrm{Al}_{2} \mathrm{O}_{3}$ nanoparticles in the $\mathrm{Ni}-\mathrm{Co}$ matrix.

It has been suggested that $\mathrm{Al}_{2} \mathrm{O}_{3}$ nanoparticles may also improve deposition of $\mathrm{Ni}$ and $\mathrm{Co}$ elements in the coatings [26]. Wear resistance is also higher for $\mathrm{Ni}-\mathrm{Co} / \mathrm{Al}_{2} \mathrm{O}_{3}$ compared to their alloy counterparts and this too increases with increases in nanoparticle content.

\subsection{Effect of SiC Nanoparticles}

$\mathrm{Ni}-\mathrm{Co} / \mathrm{SiC}$ nanocomposite coatings exhibit a porous free and dense microstructure characterized by uniformly distributed $\mathrm{SiC}$ nanoparticles throughout the deposited coating surface [126]. The phase structure of $\mathrm{Ni}-\mathrm{Co} / \mathrm{SiC}$ nanocomposites is predominantly face centered cubic. Silicon carbide ( $\mathrm{SiC}$ ) is a chemically inert semi-conductor material [134]. Embedding of $\mathrm{SiC}$ nanoparticles causes a significant improvement in the corrosion resistance, wear resistance and microhardness of the deposited coatings [31]. Babak [126] reported the same findings, with the highest corrosion resistance achieved with coatings containing $8.1 \mathrm{vol} . \% \mathrm{SiC}$ nanoparticles.

In the case of $\mathrm{Ni}-\mathrm{Co} / \mathrm{SiC}$ nanocomposite coatings, it has been observed that the concentration of Co element in the electrolyte has a significant effect on $\mathrm{SiC}$ content, whereby $\mathrm{SiC}$ content increases considerably with increasing Co element concentration. Babak [135] reported that SiC content increased from 2.0 vol.\% to 8.1 vol.\% with increases in the concentration of Co in the electrolyte. This phenomenon was attributed to ease of $\mathrm{Co}^{2+}$ cations adsorbing on nanoparticle surfaces compared to $\mathrm{Ni}^{2+}$ cations. Therefore, there was an increase in the adsorbed positive charge on the surface of the $\mathrm{SiC}$ nanoparticles as the Co element concentration increased. Generally, mass transfer of positively charged $\mathrm{SiC}$ nanoparticles towards the cathode surface is enhanced since there is an increase in the electrophoresis force exerted on them [28]. However, when the metallic cations become saturated on the $\mathrm{SiC}$ nanoparticle surface, a decrease in $\mathrm{SiC}$ content with increasing Co element concentration is observed.

Wear rate has been reported to increase with increases in SiC nanoparticle content in Ni-Co matrices [60]. As more content of $\mathrm{SiC}$ nanoparticles is added into the coatings, the grain refining and dispersion strengthening effects become magnified thereby improving the wear resistance of the nanocomposite coatings.

\subsection{Effect of $\mathrm{ZrO}_{2}$ Nanoparticles}

$\mathrm{ZrO}_{2}$ nanoparticles are known for their fracture toughness, stress induced transformation, and strength [136-138]. As such, they are an important consideration in nanocomposite coating deposition for wear protection in environments at high pressure and high temperature. $\mathrm{Ni}-\mathrm{Co} / \mathrm{ZrO}_{2}$ nanocomposite coatings also exhibit high hardness and excellent corrosion resistance.

\section{Applications}

Electrodeposited Ni-Co alloys and nanocomposites exhibit unique properties and, as such, they are used for a wide variety of industrial applications. Their combined reduced localized corrosion and 
microhardness greatly improves protective coating performance. These coatings can therefore be used to protect less wear resistant and softer substrate surfaces for use in industry.

Karpuz et al. [68] reported that Ni-Co coatings electrodeposited from baths containing nickel sulfamate, boric acid and cobalt sulfate have potential for application in magnetic sensors. These magnetic properties of deposited $\mathrm{Ni}-\mathrm{Co}$ coatings and their nanocomposites offers attractive potential to serve as soft magnets for motors, power supplies and high-efficiency transformers [3].

$\mathrm{Ni}-\mathrm{Co}$ hydroxide nanosheets have been identified as candidates for pseudocapacitor application to meet the ever-growing demand for new energy storage devices. Pu J, et al. [139] researched on $\mathrm{Ni}-\mathrm{Co}$ layered double hydroxides (LDHs) nanosheets and reported that the nanosheets exhibited excellent specific capacitance of $1734 \mathrm{~F} \mathrm{~g}^{-1}$ at $6 \mathrm{~A} \mathrm{~g}^{-1}$. The nanosheets also exhibited better stability with a capacitance retention of $86 \%$ in the galvanostatic charge-discharge test after 1000 cycles.

\section{Future Scope and Recommendations}

Key areas that have been identified for future additional research include $[140,141]$ :

(i) Corrosion resistance behavior in varying environments, such as steady and dynamic conditions.

(ii) Tribological properties such as dry and wet abrasive behavior under controlled loads.

(iii) Electroless deposition of Ni-Co coatings, which offers a more competitive and specialized option.

(iv) Thermal oxidation resistance of Ni-Co alloy matrices.

(v) More efficient electrolyte agitation techniques such as submerged jet impingement and flow cells, jet eductors, and ultrasound.

(vi) Extensive research on hydrogen evolution mitigation in electrodeposited Ni-based coatings by using pulse electrodeposition and additives.

(vii) Use of response surface methodology to optimize the Ni-Co electrodeposition process and increase accuracy of the desired properties and also predict tested properties.

Hydrogen evolution affects the coating structure of deposited coatings. Several approaches have been used with different materials to great success. Kannan and Wallipa [114] coated a magnesium alloy with calcium phosphate using constant-potential and pulse-potential methods and analyzed the in vitro corrosion resistance properties. It was reported that the polarization resistance of pulse-potential deposited coatings was three times higher than that exhibited by constant-potential deposited coatings, and this was associated with the calcium phosphate particles being closely packed for pulse-potential coatings. This provides an interesting approach that can be researched on using $\mathrm{Ni}$ and $\mathrm{Ni}-\mathrm{Co}$ based coatings.

Several other hypotheses have been postulated for the mitigation of hydrogen evolution in the electrodeposition process in different coatings. In past research, an organic solvent (ethanol) was added to the electrolyte bath to slow down hydrogen evolution on a magnesium alloy by decreasing conductivity of the plating solution, resulting in decreased hydrogen bubble bursting rate and hence a highly dense coating was deposited [142]. This approach of slowing down hydrogen evolution by decreasing the conductivity, however, results in lower deposition rates. Metal deposition utilizes the $\mathrm{OH}^{-}$ions generated during $\mathrm{H}_{2} \mathrm{O}$ breakdown whereby the metallic ions are reduced to form the metal. The mechanisms for hydrogen generation and metal-hydroxyl ion adsorption are shown in Equations (14)-(18) [143,144].

$$
\begin{gathered}
2 \mathrm{H}_{2} \mathrm{O}+2 \mathrm{e}^{-}=\mathrm{H}_{2}+2 \mathrm{OH}^{-} \\
2 \mathrm{H}+2 \mathrm{e}^{-}=\mathrm{H}_{2} \\
\mathrm{M}^{2+}+\mathrm{OH}^{-}=\mathrm{M}(\mathrm{OH})^{+} \\
\mathrm{M}(\mathrm{OH})^{+} \rightarrow \mathrm{M}(\mathrm{OH})_{\mathrm{ads}}^{+} \\
\mathrm{M}(\mathrm{OH})_{\mathrm{ads}}^{+}+2 \mathrm{e}^{-}=\mathrm{M}+\mathrm{OH}^{-}
\end{gathered}
$$


where $\mathrm{M}$ can be Ni or Co ions. As such, a balance must be struck between the rate of hydrogen evolution and the deposition rate, and this offers an interesting area for research and application in $\mathrm{Ni}$ and $\mathrm{Ni}-\mathrm{Co}$ based electrodeposited coatings. Other additives used include polyethylene glycol and di-sodium ethylenediamine tetraacetic acid (EDTA) in pulse copper deposition, and it has been reported that this improves the throwing power, current efficiency, and thickness of deposited coatings [145]. These additives can also be considered for electrodeposited $\mathrm{Ni}$ and $\mathrm{Ni}-\mathrm{Co}$ based coatings.

It is advisable to use larger sample sizes because they hinder the manifestation of edge effects that are common in smaller sample sizes. This is especially common where the current density used is high with respect to the substrate's surface area.

The adhesive force that exists between the substrate and the coatings plays a major role in the wear resistance of the material. As such, ensuring a good bond exists between the deposit and substrate surface is key. Copper electrodes tend to exhibit better adhesive properties compared to their steel counterparts, but they are also more costly. Using a pre-treatment step offers the chance to improve this bond, especially where the substrate is made of steel. From personal experience, a triple immersion procedure of electronic cleaning can be used for better adhesion. This comprises of degreasing using electro-hydrostatic fluid, then removal of oxide layer by passing the substrates through a strong activating solution, and finally removal of carbon-black by passing the substrates through a weak activating solution [49]. A similar pre-treatment process has been used in other coatings like Ni-W nanocomposite coatings with good adhesion translating to superb wear resistance achieved [146]. This pre-treatment process provides interesting possibilities for future use in Ni-Co alloys and nanocomposites. De-ionized water should be used to clean the substrate surface after each pre-treatment step.

Research shows that orientation of electrodes in the electrolyte plays a major role in the deposition process. Results obtained from $\mathrm{Ni}-\mathrm{Co}$ deposition suggest that the sediment deposition technique (SCD) is more favorable compared to conventional deposition technique. Ni-Co alloy and nanocomposite coatings deposited from the SCD technique have exhibited superior properties of higher Co content and higher nanoparticle content which translate to better microhardness, and improved wear and corrosion resistance of the deposited coatings. As such, selection of SCD in DC electrodeposition of $\mathrm{Ni}-\mathrm{Co}$ composites should be considered for further research. Based on current trends, it can be seen that owing to their exceptional wear resistance and corrosion properties, deposited Ni-Co alloys and their nanocomposites are strong contenders for further application in the aviation industry, for use in jet engine fabrication, automotive engineering, textiles and general engineering. In recent years, a keen interest has developed in specialized engineering where deposited coatings consist of mixed functional properties, as well as deposition of superhydrophobic surface coatings which exhibit excellent wear and corrosion resistance, better self-cleaning and good tribological properties.

In essence, nanoparticles can be selected to match the desired properties of any coating, and with such capacity for discovery coupled with the ever-growing need of better material properties, the possibilities for future applications are endless.

Author Contributions: Conceptualization, N.S.M. and M.K.; methodology, N.S.M., and Y.Z.; validation, N.S.M. and M.K.; formal analysis, N.S.M. and L.Y.; investigation, N.S.M., Y.Z., and N.J.N.; resources, M.K.; writing—original draft preparation, N.S.M.; G.V.B., and N.J.N.; writing-review and editing, N.S.M., Y.Z., and M.K.; visualization, N.S.M.; G.V.B., and L.Y.; supervision, M.K.; project administration, M.K.; funding acquisition, M.K. All authors have read and agreed to the published version of the manuscript.

Funding: This research was funded by the Technology development programmer for the Northern Jiangsu area, grant number BN2014019.

Conflicts of Interest: The authors declare no conflict of interest. The funders had no role in the design of the study; in the collection, analyses, or interpretation of data; in the writing of the manuscript, or in the decision to publish the results. 


\section{References}

1. Martin, P. Introduction to Surface Engineering and Functionally Engineered Materials; John Wiley \& Sons: New York, NY, USA, 2011.

2. Shriram, S.; Mohan, S.; Renganathan, N.G.; Venkatachalam, R. Electrodeposition of nanocrystalline nickel-A brief review. Int. J. Surf. Eng. Coat. 2000, 78, 194-197. [CrossRef]

3. Gurrappa, I.; Binder, L. Electrodeposition of nanostructured coatings and their characterization-A review. Sci. Technol. Adv. Mat. 2008, 9, 1-11. [CrossRef] [PubMed]

4. Qiao, G.; Jing, T.; Wang, N.; Gao, Y.; Zhao, X.; Zhou, J.; Wang, W. High-speed jet electrodeposition and microstructure of nanocrystalline Ni-Co alloys. Electrochim. Acta 2005, 51, 85-92. [CrossRef]

5. Tury, B.; Lakatos-Varsányi, M.; Roy, S. Ni-Co alloys plated by pulse currents. Surf. Coat. Technol. 2006, 200, 6713-6717. [CrossRef]

6. Chang, L.; Guo, H.; An, M. Electrodeposition of $\mathrm{Ni}-\mathrm{Co} / \mathrm{Al}_{2} \mathrm{O}_{3}$ composite coating by pulse reverse method under ultrasonic condition. Mater. Lett. 2008, 62, 3313-3315. [CrossRef]

7. Wielage, B.; Lampke, T.; Zacher, M.; Dietrich, D. Electroplated nickel composites with micron-to nano-sized particles. Key Eng. Mater. 2008, 384, 283-309. [CrossRef]

8. Schlesinger, M.; Paunovic, M. Modern Electroplating; John Wiley \& Sons: New York, USA, 2011.

9. Prasad, M.; Chokshi, A. Superplasticity in electrodeposited nanocrystalline nickel. Acta Mater. 2010, 58, 5724-5736. [CrossRef]

10. Saraev, D.; Miller, R.E. Atomic-scale simulations of nanoindentation-induced plasticity in copper crystals with nanometer-sized nickel coatings. Acta Mater. 2006, 54, 33-45. [CrossRef]

11. Kim, D.; Kim, M.K.; Son, J.T.; Kim, H.G. Effect of target properties on deposition of lithium nickel cobalt oxide thin-films using RF magnetron sputtering. J. Power Sources. 2002, 108, 239-244. [CrossRef]

12. Bakhit, B.; Akbari, A. Nanocrystalline Ni-Co alloy coatings: Electrodeposition using horizontal electrodes and corrosion resistance. J. Coat. Technol. Res. 2013, 10, 285-295. [CrossRef]

13. Rashkova, V.; Kitova, S.; Konstantinov, I.; Vitanov, T. Vacuum evaporated thin films of mixed cobalt and nickel oxides as electrocatalyst for oxygen evolution and reduction. Electrochim. Acta 2002, 47, 1555-1560. [CrossRef]

14. Koikeda, T.; Fujiwara, S.; Chikazumi, S. Perpendicular anisotropy of evaporated magnetic iron-nickel and cobalt-nickel thin films. J. Phys. Soc. Jpn. 1966, 21, 1914-1921. [CrossRef]

15. Dharmadasa, I.; Haigh, J. Strengths and advantages of electrodeposition as a semiconductor growth technique for applications in macroelectronic devices. J. Electrochem. Soc. 2006, 153, G47-G52. [CrossRef]

16. Srivastava, M.; Selvi, V.E.; Grips, V.K.W.; Rajam, K.S. Corrosion resistance and microstructure of electrodeposited nickel-cobalt alloy coatings. Surf. Coat. Technol. 2006, 201, 3051-3060. [CrossRef]

17. Yang, X.; Li, Q.; Zhang, S.; Gao, H.; Luo, F.; Dai, Y. Electrochemical corrosion behaviors and corrosion protection properties of $\mathrm{Ni}-\mathrm{Co}$ alloy coating prepared on sintered NdFeB permanent magnet. J. Solid. State. Electr. 2010, 14, 1601-1608. [CrossRef]

18. Ranjith, B.; Kalaignan, G.P. Ni-Co- $\mathrm{TiO}_{2}$ nanocomposite coating prepared by pulse and pulse reversal methods using acetate bath. Appl. Surf. Sci. 2010, 257, 42-47. [CrossRef]

19. Wang, G.; Chan, K.; Zhang, K. Low temperature superplasticity of nanocrystalline electrodeposited Ni-Co alloy. Scr. Mater. 2006, 54, 765-770. [CrossRef]

20. Wang, L.; Gao, Y.; Xue, Q.; Liu, H.; Xu, T. Microstructure and tribological properties of electrodeposited Ni-Co alloy deposits. Appl. Surf. Sci. 2005, 242, 326-332. [CrossRef]

21. Hassani, S.; Raeissi, K.; Golozar, M. Effects of saccharin on the electrodeposition of Ni-Co nanocrystalline coatings. J. Appl. Electrochem. 2008, 38, 689-694. [CrossRef]

22. Hansal, W.E.G.; Tury, B.; Halmdienst, M.; Varsányi, M.L.; Kautek, W. Pulse reverse plating of Ni-Co alloys: Deposition kinetics of Watts, sulfamate and chloride electrolytes. Electrochim. Acta 2006, 52, 1145-1151. [CrossRef]

23. Gogotsi, Y. Nanomaterials Handbook; CRC Press: Florida, FL, USA, 2006.

24. Wang, C.; Chan, K. Enhanced low-temperature superplasticity of Ni-Co alloy by addition of nano-Si ${ }_{3} \mathrm{Ni}_{4}$ particles. Mat. Sci. Eng. A-Struct. 2008, 491, 266-269. [CrossRef]

25. Afshar, A.; Ghorbani, M.; Mazaheri, M. Electrodeposition of graphite-bronze composite coatings and study of electroplating characteristics. Surf. Coat. Technol. 2004, 187, 293-299. [CrossRef] 
26. Tian, B.; Cheng, Y. Electrolytic deposition of $\mathrm{Ni}-\mathrm{Co}-\mathrm{Al}_{2} \mathrm{O}_{3}$ composite coating on pipe steel for corrosion/ erosion resistance in oil sand slurry. Electrochim. Acta 2007, 53, 511-517. [CrossRef]

27. Cai, F.; Jiang, C.; Fu, P.; Ji, V. Effects of Co contents on the microstructures and properties of electrodeposited $\mathrm{NiCo}-\mathrm{Al}$ composite coatings. Appl. Surf. Sci. 2015, 324, 482-489. [CrossRef]

28. Wang, L.; Gao, Y.; Liu, H.; Xue, Q.; Xu, T. Effects of bivalent Co ion on the co-deposition of nickel and nano-diamond particles. Surf. Coat. Technol. 2005, 191,1-6. [CrossRef]

29. Karimzadeh, A.; Aliofkhazraei, M.; Walsh, F.C. A review of electrodeposited Ni-Co alloy and composite coatings: Microstructure, properties and applications. Surf. Coat. Technol. 2019, 372, 463-498. [CrossRef]

30. Bakhit, B.; Akbari, A. Effect of particle size and co-deposition technique on hardness and corrosion properties of Ni-Co/SiC composite coatings. Surf. Coat. Technol. 2012, 206, 4964-4975. [CrossRef]

31. Borkar, T. Electrodeposition of Nickel Composite Coatings; Oklahoma State University: Oklahoma, OK, USA, 2010.

32. Yang, Y.; Cheng, Y.F. Fabrication of Ni-Co-SiC composite coatings by pulse electrodeposition-Effects of duty cycle and pulse frequency. Surf. Coat. Technol. 2013, 216, 282-288. [CrossRef]

33. Qu, N.S.; Zhu, D.; Chan, K.C.; Lei, W.N. Pulse electrodeposition of nanocrystalline nickel using ultra narrow pulse width and high peak current density. Surf. Coat. Technol. 2003, 168, 123-128. [CrossRef]

34. Li, Y.; Jiang, H.; Tian, H. Effects of peak current density on the mechanical properties of nanocrystalline Ni-Co alloys produced by pulse electrodeposition. Appl. Surf. Sci. 2008, 254, 6865-6869. [CrossRef]

35. Dheeraj, P.R.; Patra, A.; Sengupta, S.; Das, S.; Das, K. Synergistic effect of peak current density and nature of surfactant on microstructure, mechanical and electrochemical properties of pulsed electrodeposited Ni-Co-SiC nanocomposites. J. Alloy. Compd. 2017, 729, 1093-1107. [CrossRef]

36. Padmanabhan, K. Grain boundary sliding controlled flow and its relevance to superplasticity in metals, alloys, ceramics and intermetallics and strain-rate dependent flow in nanostructured materials. J. Mater. Sci. 2009, 44, 2226-2238. [CrossRef]

37. Chung, C.K.; Chang, W. Effect of pulse frequency and current density on anomalous composition and nanomechanical property of electrodeposited Ni-Co films. Thin Solid Film. 2009, 517, 4800-4804. [CrossRef]

38. Gyftou, P.; Pavlatou, E.; Spyrellis, N. Effect of pulse electrodeposition parameters on the properties of Ni/nano-SiC composites. Appl. Surf. Sci. 2008, 254, 5910-5916. [CrossRef]

39. Tury, B.; Lakatos-Varsányi, M.; Roy, S. Effect of pulse parameters on the passive layer formation on pulse plated Ni-Co alloys. Appl. Surf. Sci. 2007, 253, 3103-3108. [CrossRef]

40. Chang, L.M.; An, M.Z.; Guo, H.F.; Shi, S.Y. Microstructure and properties of Ni-Co/nano- $\mathrm{Al}_{2} \mathrm{O}_{3}$ composite coatings by pulse reversal current electrodeposition. Appl. Surf. Sci. 2006, 253, 2132-2137. [CrossRef]

41. Karakus, C.; Chin, D.T. Metal distribution in jet plating. J. Electrochem. Soc. 1994, 141, 691. [CrossRef]

42. Wang, W.; Hou, F.Y.; Wang, H.; Guo, H.T. Fabrication and characterization of $\mathrm{Ni}^{-} \mathrm{ZrO}_{2}$ composite nano-coatings by pulse electrodeposition. Scr. Mater. 2005, 53, 613-618. [CrossRef]

43. Chandrasekar, M.S.; Pushpavanam, M. Pulse and pulse reverse plating-Conceptual, advantages and applications. Electrochim. Acta 2008, 53, 3313-3322. [CrossRef]

44. Podlaha, E.; Landolt, D. Pulse-Reverse Plating of Nanocomposite Thin Films. J. Electrochem. Soc. 1997, 144, L200. [CrossRef]

45. Vidrine, A.; Podlaha, E. Composite Electrodeposition of Ultrafine $\gamma$-Alumina Particles in Nickel Matrices; Part I: Citrate and chloride electrolytes. J. Appl. Electrochem. 2001, 31, 461-468. [CrossRef]

46. Xiong-Skiba, P.; Engelhaupt, D.; Hulguin, R.; Ramsey, B. Effect of pulse plating parameters on the composition of alumina/nickel composite. J. Electrochem. Soc. 2005, 152, C571-C576. [CrossRef]

47. Sáez, V.; Gonzalez, V.; Iniesta, J.; Frías, A.; Aldaz, A. Electrodeposition of $\mathrm{PbO}_{2}$ on glassy carbon electrodes: Influence of ultrasound frequency. Electrochem. Commun. 2004, 6, 757-761. [CrossRef]

48. Touyeras, F.; Hihn, J.Y.; Bourgoin, X.; Jacques, B.; Hallez, L.; Branger, V. Effects of ultrasonic irradiation on the properties of coatings obtained by electroless plating and electro plating. Ultrason. Sonochem. 2005, 12, 13-19. [CrossRef] [PubMed]

49. Mbugua, N.S.; Kang, M.; Li, H.; Liu, Y.; Joseph, N.; Zhang, Y. The Influence of Co Concentration on the Properties of Conventionally Electrodeposited Ni-Co- $\mathrm{Al}_{2} \mathrm{O}_{3}-\mathrm{SiC}$ Nanocomposite Coatings. Prot. Met. Phys. Chem. 2020, 56, 94-102. [CrossRef]

50. Popov, K.; Grgur, B.; Djokić, S.S. Fundamental Aspects of Electrometallurgy; Kluwer Academic Publishers: Moscow, Russia, 2007. 
51. Wu, G.; Li, N.; Wang, D.L.; Zhou, D.R.; Xu, B.Q.; Mitsuo, K. Effect of $\alpha-\mathrm{Al}_{2} \mathrm{O}_{3}$ particles on the electrochemical codeposition of Co-Ni alloys from sulfamate electrolytes. Mater. Chem. Phys. 2004, 87, 411-419. [CrossRef]

52. Yari, S.; Dehghanian, C. Deposition and characterization of nanocrystalline and amorphous Ni-W coatings with embedded alumina nanoparticles. Ceram. Int. 2013, 39, 7759-7766. [CrossRef]

53. Prabu, S.; Wang, H.W. Factors Affecting the Electrodeposition of Aluminum Metal in an Aluminum Chloride-Urea Electrolyte Solution. J. Chin. Chem. Soc-Taip. 2017, 64, 1467-1477. [CrossRef]

54. Idris, J.; Christian, C.; Gaius, E. Nanocrystalline Ni-Co alloy synthesis by high speed electrodeposition. J. Nanomater. 2013, 2013, 1-8. [CrossRef]

55. Goto, Y.; Kamebuchi, Y.; Hagio, T.; Kamimoto, Y.; Ichino, R.; Bessho, T. Electrodeposition of copper/carbonous nanomaterial composite coatings for heat-dissipation materials. Coatings 2018, 8, 5. [CrossRef]

56. Srivastava, M.; Grips, V.W.; Rajam, K. Influence of $\mathrm{Co}$ on $\mathrm{Si}_{3} \mathrm{~N}_{4}$ incorporation in electrodeposited Ni. J. Alloy. Compd. 2009, 469, 362-365. [CrossRef]

57. Bakhit, B.; Akbari, A. Synthesis and characterization of $\mathrm{Ni}-\mathrm{Co} / \mathrm{SiC}$ nanocomposite coatings using sediment co-deposition technique. J. Alloy. Compd. 2013, 560, 92-104. [CrossRef]

58. Bercot, P.; Pena-Munoz, E.; Pagetti, J. Electrolytic composite Ni-PTFE coatings: An adaptation of Guglielmi's model for the phenomena of incorporation. Surf. Coat. Technol. 2002, 157, 282-289. [CrossRef]

59. Lozano-Morales, A.; Podlaha, E. The Effect of $\mathrm{Al}_{2} \mathrm{O}_{3}$ Nanopowder on Cu Electrodeposition. J. Electrochem. Soc. 2004, 151, C478-C483. [CrossRef]

60. Shi, L.; Sun, C.; Gao, P.; Zhou, F.; Liu, W. Mechanical properties and wear and corrosion resistance of electrodeposited Ni-Co/SiC nanocomposite coating. Appl. Surf. Sci. 2006, 252, 3591-3599. [CrossRef]

61. Tian, L.; Xu, J.; Xiao, S. The influence of $\mathrm{pH}$ and bath composition on the properties of Ni-Co coatings synthesized by electrodeposition. Vacuum. 2011, 86, 27-33. [CrossRef]

62. Gomez, E.; Pane, S.; Valles, E. Electrodeposition of Co-Ni and Co-Ni-Cu systems in sulphate-citrate medium. Electrochim. Acta 2005, 51, 146-153. [CrossRef]

63. Oriňáková, R.; Orinak, A.; Vering, G.; Talian, I.; Smith, M.R.; Arlinghaus, H. Influence of pH on the electrolytic depositon of Ni-Co Film. Thin Solid Film. 2008, 516, 3045-3050. [CrossRef]

64. Ma, C.; Wang, S.C.; Low, C.T.J.; Wang, L.P.; Walsh, F.C. Effects of additives on microstructure and properties of electrodeposited nanocrystalline Ni-Co alloy coatings of high cobalt content. Int. J. Surf. Eng. Coat. 2014, 92, 189-195. [CrossRef]

65. Puippe, J.C.; Leaman, F. Theory and Practice of Pulse Plating; Amer Electroplaters Soc.: Orlando, FL, USA, 1986.

66. Lupi, C.; Dell'Era, A.; Pasquali, M.; Imperatori, P. Composition, morphology, structural aspects and electrochemical properties of Ni-Co alloy coatings. Surf. Coat. Technol. 2011, 205, 5394-5399. [CrossRef]

67. Fan, C.; Piron, D. Study of anomalous nickel-cobalt electrodeposition with different electrolytes and current densities. Electrochim. Acta 1996, 41, 1713-1719. [CrossRef]

68. Karpuz, A.; Kockar, H.; Alper, M.; Karaagac, O.; Haciismailoglu, M. Electrodeposited Ni-Co films from electrolytes with different Co contents. Appl. Surf. Sci. 2012, 258, 4005-4010. [CrossRef]

69. Celis, J.P.; Roos, J. Kinetics of the deposition of alumina particles from copper sulfate plating baths. J. Electrochem. Soc. 1977, 124, 1508-1511. [CrossRef]

70. Ahmad, Y.H.; Mohamed, A. Electrodeposition of nanostructured nickel-ceramic composite coatings: A review. Int. J. Electrochem. Sci. 2014, 9, 1942-1963.

71. Gomez, E.; Pane, S.; Alcobe, X.; Vallés, E. Influence of a cationic surfactant in the properties of cobalt-nickel electrodeposits. Electrochim. Acta 2006, 51, 5703-5709. [CrossRef]

72. Di Bari, G.A. Electrodeposition of nickel. In Modern Electroplating, 5th ed.; Schlesinger, M., Paunovic, M., Eds.; John Wiley \& Sons, Inc.: Hoboken, NJ, USA, 2000; Volume 3, pp. 79-114.

73. Gezerman, A.O.; Corbacioglu, B.D. Analysis of the characteristics of nickel-plating baths. Int. J. Chem. 2010, 2, 124-137. [CrossRef]

74. Ispas, A.; Matsushima, H.; Bund, A.; Bozzini, B. A study of external magnetic-field effects on nickel-iron alloy electrodeposition, based on linear and non-linear differential AC electrochemical response measurements. Electroanal. Chem. 2011, 651, 197-203. [CrossRef]

75. Ramazani, A.; Asgari, V.; Montazer, A.H.; Kashi, M.A. Tuning magnetic fingerprints of FeNi nanowire arrays by varying length and diameter. Curr. Appl. Phys. 2015, 15, 819-828. [CrossRef]

76. Tsuru, Y.; Nomura, M.; Foulkes, F. Effects of boric acid on hydrogen evolution and internal stress in films deposited from a nickel sulfamate bath. J. Appl. Electrochem. 2002, 32, 629-634. [CrossRef] 
77. Gadad, S.; Harris, T.M. Oxygen Incorporation during the Electrodeposition of Ni, Fe, and Ni-Fe Alloys. J. Electrochem. Soc. 1998, 145, 3699. [CrossRef]

78. Karwas, C.; Hepel, T. Influence of Boric Acid on Electrodeposition and Stripping of Ni-Zn Alloys. J. Electrochem. Soc. 1988, 135, 839. [CrossRef]

79. Saubestre, E.B. The Chemistry of Watts Nickel Plating Solutions. Plating 1958, 45, 927-936.

80. Tilak, B.; Gendron, A.; Mosoiu, M. Borate buffer equilibria in nickel refining electrolytes. J. Appl. Electrochem. 1977, 7, 495-500. [CrossRef]

81. Šupicová, M.; Rozik, R.; Tmkova, L.; Oriňáková, R.; Gálová, M. Influence of boric acid on the electrochemical deposition of Ni. J. Solid State Electr. 2006, 10, 61-68. [CrossRef]

82. Yin, K.M.; Lin, B.T. Effects of boric acid on the electrodeposition of iron, nickel and iron-nickel. Surf. Coat. Technol. 1996, 78, 205-210. [CrossRef]

83. Abyaneh, M.; Hashemi-Pour, M. The effect of the concentration of boric acid on the kinetics of electrocrystallization of nickel. Int. J. Surf. Eng. Coat. 1994, 72, 23-26. [CrossRef]

84. Narasimman, P.; Pushpavanama, M.; Periasamyb, V. Effect of surfactants on the electrodeposition of Ni-SiC composites. Port. Electrochim. Acta 2012, 30,1-14. [CrossRef]

85. Li, Q.; Fu, W.; Mu, Y.; Zhang, W.; Lv, P.; Zhou, L.; Yang, H.; Chi, K.; Yang, L. The effects of CTAB concentration on the properties of electrodeposited cadmium telluride films. CrystEngComm 2014, 16, 5227-5233. [CrossRef]

86. Kılıc, F.; Gul, H.; Aslan, S.; Alp, A.; Akbulut, H. Effect of CTAB concentration in the electrolyte on the tribological properties of nanoparticle $\mathrm{SiC}$ reinforced $\mathrm{Ni}$ metal matrix composite (MMC) coatings produced by electrodeposition. Colloid Surf. A. 2013, 419, 53-60. [CrossRef]

87. Sabri, M.; Sarabi, A.A.; Kondelo, S.M.N. The effect of sodium dodecyl sulfate surfactant on the electrodeposition of Ni-alumina composite coatings. Mater. Chem. Phys. 2012, 136, 566-569. [CrossRef]

88. Baghal, S.M.L.; Amadeh, A.; Sohi, M.H.; Hadavi, S.M.M. The effect of SDS surfactant on tensile properties of electrodeposited Ni-Co/SiC nanocomposites. Mat. Sci. Eng. A-Struct. 2013, 559, 583-590. [CrossRef]

89. Sen, R.; Bhattacharya, S.; Das, S.; Das, K. Effect of surfactant on the co-electrodeposition of the nano-sized ceria particle in the nickel matrix. J. Alloy. Compd. 2010, 489, 650-658. [CrossRef]

90. Gamburg, Y.D.; Zangari, G. Theory and Practice of Metal Electrodeposition; Springer Science \& Business Media: Berlin, Germany, 2011.

91. Guo, C.; Zuo, Y.; Zhao, X.; Zhao, J.; Xiong, J. Effects of surfactants on electrodeposition of nickel-carbon nanotubes composite coatings. Surf. Coat. Technol. 2008, 202, 3385-3390. [CrossRef]

92. Pradhan, A.K.; Das, S. Pulse reverse electrodeposition of Cu-SiC nanocomposite coating: Effects of surfactants and deposition parameters. Met. Mater. Trans. A 2014, 45, 5708-5720. [CrossRef]

93. Ger, M.D. Electrochemical deposition of nickel/SiC composites in the presence of surfactants. Mater. Chem. Phys. 2004, 87, 67-74. [CrossRef]

94. Li, Y.; Jiang, H.; Wang, D.; Ge, H. Effects of saccharin and cobalt concentration in electrolytic solution on microhardness of nanocrystalline Ni-Co alloys. Surf. Coat. Technol. 2008, 202, 4952-4956. [CrossRef]

95. Weil, R.; Cook, H. Electron-Microscopic Observations of the Structure of Electroplated Nickel. J. Electrochem. Soc. 1962, 109, 295. [CrossRef]

96. Wang, G.; Jiang, S.; Zhen, L.U.; Zhang, K. Preparation and tensile properties of $\mathrm{Al}_{2} \mathrm{O}_{3} / \mathrm{Ni}$-Co nanocomposites. T Nonferr. Met. Soc. 2011, 21, s374-s379. [CrossRef]

97. Koch, C. Optimization of strength and ductility in nanocrystalline and ultrafine grained metals. Scr. Mater. 2003, 49, 657-662. [CrossRef]

98. Yin, W.M.; Whang, S.H.; Mirshams, R. Effect of interstitials on tensile strength and creep in nanostructured Ni. Acta Mater. 2005, 53, 383-392. [CrossRef]

99. Hadian, S.; Gabe, D. Residual stresses in electrodeposits of nickel and nickel-iron alloys. Surf. Coat. Technol. 1999, 122, 118-135. [CrossRef]

100. Dzedzina, R.; Hagarova, M. Effect of Additive on the Internal Stress in Galvanic Coatings. Int. J. Electrochem. Sci. 2013, 8, 8291-8298.

101. Kubart, T.; Mala, Z.; Novak, R.; Novakova, D. Effect of coated edge geometry on internal stress distribution in multilayered coatings. Surf. Coat. Technol. 2001, 142, 610-614. [CrossRef]

102. El-Sherik, A.; Shirokoff, J.; Erb, U. Stress measurements in nanocrystalline Ni electrodeposits. J. Alloy. Compd. 2005, 389, 140-143. [CrossRef] 
103. Chen, C.J.; Lin, K.L. Internal stress and adhesion of amorphous Ni-Cu-P alloy on aluminum. Thin Solid Film. 2000, 370, 106-113. [CrossRef]

104. Bai, A.; Hu, C.C. Effects of electroplating variables on the composition and morphology of nickel-cobalt deposits plated through means of cyclic voltammetry. Electrochim. Acta 2002, 47, 3447-3456. [CrossRef]

105. Go, E.; Ramirez, J.; Valle, E. Electrodeposition of Co-Ni alloys. J. Appl. Electrochem. 1998, 28, 71-79.

106. Rafailović, L.D.; Karnthaler, H.P.; Trisovic, T.; Minić, D.M. Microstructure and mechanical properties of disperse Ni-Co alloys electrodeposited on Cu substrates. Mater. Chem. Phys. 2010, 120, 409-416. [CrossRef]

107. Barbir, F. Transition to renewable energy systems with hydrogen as an energy carrier. Energy 2009, 34, 308-312. [CrossRef]

108. Veziro, T.N.; Barbir, L.F. Hydrogen: The wonder fuel. Int. J. Hydrog. Energy 1992, 17, 391-404. [CrossRef]

109. Bockris, J.N.; Veziroǧlu, T.M. A solar-hydrogen economy for USA. Int. J. Hydrog. Energy 1983, 8, 323-340. [CrossRef]

110. Mazloomi, K.; Gomes, C. Hydrogen as an energy carrier: Prospects and challenges. Renew. Sust. Energy Rev. 2012, 16, 3024-3033. [CrossRef]

111. Ganley, J.C. High temperature and pressure alkaline electrolysis. Int. J. Hydrog. Energy 2009, 34, $3604-3611$. [CrossRef]

112. Vijayakumar, J.; Mohan, S.; Kumar, S.A.; Suseendiran, S.R.; Pavithra, S. Electrodeposition of Ni-Co-Sn alloy from choline chloride-based deep eutectic solvent and characterization as cathode for hydrogen evolution in alkaline solution. Int. J. Hydrog. Energy 2013, 38, 10208-10214. [CrossRef]

113. Lasia, A.; Rami, A. Kinetics of hydrogen evolution on nickel electrodes. J. Electroanal Chem. 1990, 294, 123-141. [CrossRef]

114. Kannan, M.B.; Wallipa, O. Potentiostatic pulse-deposition of calcium phosphate on magnesium alloy for temporary implant applications-An in vitro corrosion study. Mat. Sci. Eng. C 2013, 33, 675-679. [CrossRef]

115. Baghal, S.M.L.; Sohi, M.H.; Amadeh, A. A functionally gradient nano-Ni-Co/SiC composite coating on aluminum and its tribological properties. Surf. Coat. Technol. 2012, 206, 4032-4039. [CrossRef]

116. Dieter, P.P. Mechanical Metallurgy; McGraw-Hill Book Co.: New York, NY, USA, 1986.

117. Jeong, D.H.; Gonzalez, F.; Palumbo, G.; Aust, K.T.; Erb, U. The effect of grain size on the wear properties of electrodeposited nanocrystalline nickel coatings. Scripta. Mater. 2001, 44, 493-499. [CrossRef]

118. Kim, D.; Park, D.Y.; Yoo, B.Y.; Sumodjo, P.T.A.; Myung, N.V. Magnetic properties of nanocrystalline iron group thin film alloys electrodeposited from sulfate and chloride baths. Electrochim. Acta 2003, 48, 819-830. [CrossRef]

119. Kusakabe, S.; Rawls, H.R.; Hotta, M. Relationship between thin-film bond strength as measured by a scratch test, and indentation hardness for bonding agents. Dent. Mater. 2016, 32, e55-e62. [CrossRef]

120. Jiang, W.; Shen, L.; Xu, M.; Wang, Z.; Tian, Z. Mechanical properties and corrosion resistance of Ni-Co-SiC composite coatings by magnetic field-induced jet electrodeposition. J. Alloy. Compd. 2019, 791, 847-855. [CrossRef]

121. Chen, X.H.; Chen, C.S.; Xiao, H.N.; Cheng, F.Q.; Zhang, G.; Yi, J.G. Corrosion behavior of carbon nanotubes-Ni composite coating. Surf. Coat. Technol. 2005, 191, 351-356. [CrossRef]

122. Rogal, Ł.; Kalita, D.; Tarasek, A.; Bobrowski, P.; Czerwinski, F. Effect of SiC nano-particles on microstructure and mechanical properties of the CoCrFeMnNi high entropy alloy. J. Alloy. Compd. 2017, 708, 344-352. [CrossRef]

123. Jasim, K.M.; Rawlings, R.D.; West, D.R.F. Metal-ceramic functionally gradient material produced by laser processing. J. Mater. Sci. 1993, 28, 2820-2826. [CrossRef]

124. Cramer, S.D.; Covino, B.S. ASM Handbook; ASM international Materials Park: Ohio, OH, USA, 2003.

125. Edward, J. Coating and Surface Treatment Systems for Metals: A Comprehensive Guide to Selection; ASM International: Michigan, MI, USA, 1997.

126. Bakhit, B.; Akbari, A.; Nasirpouri, F.; Hosseini, M.G. Corrosion resistance of Ni-Co alloy and Ni-Co/SiC nanocomposite coatings electrodeposited by sediment codeposition technique. Appl. Surf. Sci. 2014, 307, 351-359. [CrossRef]

127. Ramanauskas, R.; Quintana, P.; Maldonado, L.; Pomés, R.; Pech, M.A. Corrosion resistance and microstructure of electrodeposited Zn and Zn alloy coatings. Surf. Coat. Technol. 1997, 92, 16-21. [CrossRef] 
128. García, I.; Conde, A.; Langelaan, G.; Fransaer, J.; Celis, J.P. Improved corrosion resistance through microstructural modifications induced by codepositing SiC-particles with electrolytic nickel. Corros. Sci. 2003, 45, 1173-1189. [CrossRef]

129. Dieter, G.E.; Bacon, D. Mechanical Metallurgy; McGraw Hill: New York, NY, USA, 1986.

130. Pavlatou, E.A.; Stroumbouli, P.; Gyftou, P.; Spyrellis, N. Hardening effect induced by incorporation of SiC particles in nickel electrodeposits. J. Appl. Electrochem. 2006, 36, 385-394. [CrossRef]

131. Zimmerman, A.F.; Palumbo, G.; Aust, K.T.; Erb, U. Mechanical properties of nickel silicon carbide nanocomposites. Mat. Sci. Eng. A-Struct. 2002, 328, 137-146. [CrossRef]

132. Zhou, Y.B.; Ding, Y.Z. Oxidation resistance of co-deposited Ni-SiC nanocomposite coating. Trans. Nonferr. Met. Soc. 2007, 17, 925-928. [CrossRef]

133. Shi, L.; Sun, C.; Liu, W. Electrodeposited nickel-cobalt composite coating containing MoS2. Appl. Surf. Sci. 2008, 254, 6880-6885. [CrossRef]

134. Bhatnagar, M.; Baliga, B.J. Comparison of $6 \mathrm{H}-\mathrm{SiC}, 3 \mathrm{C}-\mathrm{SiC}$, and Si for power devices. IEEE Trans. Electron. Dev. 1993, 40, 645-655. [CrossRef]

135. Bakhit, B. The influence of electrolyte composition on the properties of Ni-Co alloy coatings reinforced by SiC nano-particles. Surf. Coat. Technol. 2015, 275, 324-331. [CrossRef]

136. Yang, G.; Yin, L.; Fang, X.; Fang, M.; Liu, Y.; Huang, Z.; Liu, B. Fabrication and liquid-solid, two-phase erosion wear behaviour of $\beta$-Sialon ceramic from pyrophyllite by carbothermal reduction and nitridation. Ceram. Int. 2014, 40, 10737-10741. [CrossRef]

137. Basu, B.; Vleugels, J.; Van Der Biest, O. Microstructure-toughness-wear relationship of tetragonal zirconia ceramics. J. Eur. Ceram. Soc. 2004, 24, 2031-2040. [CrossRef]

138. Beiyue, M.; Jingkun, Y. Phase composition of $\mathrm{SiC}-\mathrm{ZrO}_{2}$ composite materials synthesized from zircon doped with $\mathrm{La}_{2} \mathrm{O}_{3}$. J. Rare Earths 2009, 27, 806-810.

139. Pu, J.; Tong, Y.; Wang, S.; Sheng, E.; Wang, Z. Nickel-cobalt hydroxide nanosheets arrays on Ni foam for pseudocapacitor applications. J. Power Sources 2014, 250, 250-256. [CrossRef]

140. Ma, C.; Wang, S.C.; Walsh, F.C. Electrodeposition of nanocrystalline nickel and cobalt coatings. Int. J. Surf. Eng. Coat. 2015, 93, 8-17. [CrossRef]

141. Walsh, F.C.; Wang, S.; Zhou, N. The electrodeposition of composite coatings: Diversity, applications and challenges. Curr. Opin. Electrochem. 2020, 20, 8-19. [CrossRef]

142. Kannan, M.B. Improving the packing density of calcium phosphate coating on a magnesium alloy for enhanced degradation resistance. J. Biomed. Mater. Res. Part. A. 2013, 101, 1248-1254. [CrossRef]

143. Tury, B.; Radnoczi, G.Z.; Radnoczi, G.; Varsányi, M.L. Microstructure properties of pulse plated Ni-Co alloy. Surf. Coat. Technol. 2007, 202, 331-335. [CrossRef]

144. Darband, G.B.; Aliofkhazraei, M.; Rouhaghdam, A.S.; Kiani, M.A. Three-dimensional Ni-Co alloy hierarchical nanostructure as efficient non-noble-metal electrocatalyst for hydrogen evolution reaction. Appl. Surf. Sci. 2019, 465, 846-862. [CrossRef]

145. Mohan, S.; Raj, V. The effect of additives on the pulsed electrodeposition of copper. Trans. IMF 2005, 83, 194-198. [CrossRef]

146. Nyambura, S.M.; Kang, M.; Zhu, J.; Liu, Y.; Zhang, Y.; Ndiithi, N.J. Synthesis and Characterization of $\mathrm{Ni}-\mathrm{W} / \mathrm{Cr}_{2} \mathrm{O}_{3}$ Nanocomposite Coatings Using Electrochemical Deposition Technique. Coatings 2019, 9, 815. [CrossRef]

(C) 2020 by the authors. Licensee MDPI, Basel, Switzerland. This article is an open access article distributed under the terms and conditions of the Creative Commons Attribution (CC BY) license (http://creativecommons.org/licenses/by/4.0/). 